\title{
El derecho a la asistencia socio-sanitaria de los ciudadanos europeos mayores de edad en Andalucía*
}

\author{
Elsa M arina Álvarez González \\ Profesora Ayudante de Derecho Administrativo \\ Universidad de Málaga
}

\section{INTRODUCCIÓN}

La asistencia socio-sanitaria se ha convertido en una de las necesidades básicas de las personas mayores. De ahí que, el nuevo Estatuto de Autonomía de Andalucía ${ }^{1}$ reconozca a las personas mayores el derecho a recibir de los poderes públicos de Andalucía una protección y una atención integral para la promoción de su autonomía personal y del envejecimiento activo, que les permita una vida digna e independiente y su bienestar social e individual, aś como a acceder a una atención gerontológica adecuada, en el ámbito sanitario, social y asistencial, y a percibir prestaciones en los términos que establezcan las leyes.

El ejercicio de este derecho estatutario y fundamental para las personas mayores y el acceso a las prestaciones socio-sanitarias cuando éstos son nacionales de la Unión Europea presenta algunos problemas de enorme relevancia jurídica que precisan de un estudio y análisis pormenorizado, lo que constituye el objeto principal de este trabajo.

* Este trabajo forma parte del convenio I+D celebrado ente el Consejo Superior de Investigaciones científicas (CSIC) -Instituto de Economía y Geografía- y el grupo de Investigación EURIE, de la UMA, al que pertenezco, para la elaboración del Proyecto "Ios Extranjeros Retirados en Andalucía: análisis y propuestas de actuación", solicitado por el Instituto de Estadística de Andalucía.

${ }^{1}$ Art. 19 Ley Orgánica 2/ 2007, de 19 de marzo, de reforma del Estatuto de Autonomía para Andalucía. 
Los gerontoinmigrantes comunitarios ( $\mathrm{GIC}$ ), terminología propia que define el ámbito subjetivo del presente estudio², en Andalucía, aunque tienen reconocidos el derecho a la asistencia socio-sanitaria por el Estatuto de Autonomía andaluz, dicho reconocimiento debe matizarse con el análisis de los problemas que plantea a estos ciudadanos europeos la legislación vigente en materia sanitaria y social.

En principio, para ser titular de los derechos reconocidos en el Estatuto de Autonomía para Andalucía, todas las personas, incluidas también, por tanto, los GIC, deben tener "vecindad administrativa" en cualquiera de los municipios de Andalucía ${ }^{3}$. Este requisito de la vecindad administrativa se exige también en la legislación social y sanitaria de la Comunidad Autónoma de Andalucía.

Así, en el ámbito social, la Ley de Atención y Protección a las Personas Mayores de Andalucía, reconoce el derecho de acceso a las prestaciones y servicios previstos en la misma a los extranjeros con "residencia" en cualquier municipio de Andalucía4; el Reglamento sobre concesión y uso de la Tarjeta Andalucía Junta Sesenta y Cinco, que permite a sus titulares acceder a las prestaciones y servicios que se establezcan al efecto en el ámbito de los servicios sociales, exige a los beneficiarios, además de tener 65 años de edad, el empadronamiento en cualquier municipio de Andalucía ${ }^{5}$. Y en el ámbito sanitario, la Ley de Salud de Andalucía ${ }^{6}$ reconoce entre los titulares de los derechos en materia sanitaria en el Sistema Sanitario Público de Andalucía a "Ios extranjeros residentes en cualesquiera de los municipios de Andalucía".

\footnotetext{
${ }^{2}$ Tal y como ha sido establecido por el grupo de investigación EURIE de la Universidad de Málaga en la obra dirigida por la profesora ECHEZARRETA FERRER, M. El Lugar Europeo de Retiro. Indicadores de excelencia para administrar la gerontoinmigración de ciudadanos de la Unión Europea en municipios españoles. Editorial Comares, Granada, 2005.

${ }^{3}$ Art. 12 Ley Orgánica 2/ 2007, de 19 de marzo, de reforma del Estatuto de Autonomía para Andalucía.

${ }^{4}$ Art. 2.1b) de la Ley 6/ 1999, de 7 de julio, de Atención y Protección a las Personas Mayores de Andalucía.

${ }^{5}$ Art. 2 Decreto 76/ 2001, de 13 de marzo, por el que se regula la concesión y uso de la Tarjeta Andalucía Junta Sesenta y Cinco.

${ }^{6}$ Art. 3 Ley 2/ 1998, de 15 de junio, de Salud de Andalucía.
} 
Por tanto, en una primera aproximación al marco jurídico-legal andaluz en materia sociosanitaria, podemos observar como las normas exigen la inscripción de los GIC en un registro público que acredite la residencia en un municipio de Andalucía, es decir, en el Padrón municipal, para poder acceder o tener derecho a las prestaciones socio-sanitarias que el sistema público andaluz ofrece. Sin embargo, sólo tras el estudio y análisis del registro municipal y de los registros socio-sanitarios se podrán aportar algunas conclusiones que no se corresponden con esta aproximación inicial.

\section{REGISTRO MUNICIPAL Y VECINDAD ADMINISTRATIVA: EL PADRÓN MUNICIPAL}

El principal registro público cuya inscripción otorga derechos y deberes a las personas en él inscritas es el Padrón municipal. Mediante el acceso a este registro se obtiene la vecindad administrativa. De ahí que la Ley $7 / 1985$, de 2 de abril, de Bases del Régimen Local (en adelante LBRL), lo defina como el registro administrativo donde constan los vecinos de un municipio (art. 16).

La inscripción en el Padrón del municipio en el que la persona reside habitualmente se configura como una obligación legal de toda persona que viva en España, y ello, para poder constituir de manera efectiva la población de un municipio, en base a la cual los municipios obtienen los recursos económicos para satisfacer las necesidades de sus ciudadanos.

Entonces, ¿deben registrarse en el Padrón municipal los GIC que se encuentren en Andalucía? La respuesta dependerá del tipo de vinculación del gerontoinmigrante con España, pues la gerontoinmigración está compuesta por una serie de tipologías intercambiables como son la de turista y residente. El paso de una tipología a otra se produce con el acto de empadronamiento.

Por tanto, parece claro que el GIC en Andalucía con vinculación de residente está obligado, al igual que el resto de los españoles, a inscribirse en el Padrón municipal. El retiro de los GIC a nuestra Comunidad Autónoma debe obligar a su inscripción en el registro municipal, para poder ser vecinos de un municipio y disfrutar de los derechos y obligaciones que ello conlleva.

El problema, no obstante, está en la necesidad de determinar cuándo el GIC pasa de la vinculación de turista a residente en Andalucía, y cuándo nace esa obligación de empadronarse en el municipio en el que reside. Además, también es importante delimitar si la vinculación de residente exige el retiro 
a nuestra Comunidad Autónoma de carácter definitivo o puede ser temporal, volviendo el GIC al país de origen determinado periodo de tiempo al año.

A estos efectos, la LBRL establece "quien viva en varios municipios deberá inscribirse únicamente en el que habite durante más tiempo al año" (art. 15), es decir, en aquél en el que se resida durante 181 días al año. Pero este precepto, está pensado para el ciudadano español que reside en varios municipios españoles al año, y resulta difícilmente aplicable a la población objeto de nuestro estudio, pues la movilidad de los GIC, más que entre dos municipios españoles, se produce entre el municipio de residencia en España y su país de origen.

En principio, si el tiempo de residencia en España es inferior al de residencia en el país de origen, no podría exigirse la obligación de empadronamiento. Pero, ¿y en el supuesto de aquéllos GIC que residen 6 meses en nuestro país y 6 meses en el país de origen? Q uizás hasta hace relativamente poco, la solución a estos interrogantes no era tarea fácil, pues la regulación del Padrón municipal que efectúa LBRL no se ha adaptado a las nuevas situaciones producidas como consecuencia del reconocimiento de las libertades comunitarias, a diferencia de las modificaciones legales producidas sobre el Padrón con respecto a los extranjeros no comunitarios?.

Sin embargo, una solución parece apuntarse en el nuevo Real Decreto 240/ 2007, de 16 de febrero, sobre entrada, libre circulación y residencia en España de ciudadanos de los Estados miembros de la U nión Europea y de otros Estados parte en el Acuerdo sobre el Espacio Económico Europeo. En él se exige la inscripción en el Registro Central de Extranjeros cuando la residencia en España es superior a tres meses, pues se parte del entendimiento de que tiene la condición/ categoría de "turista" el ciudadano europeo o del Espacio Económico Europeo que disfruta de una estancia en España inferior a tres meses.

Así pues, la vinculación del GIC con Andalucía es en calidad de turista, cuando su estancia es de carácter temporal e inferior a tres meses; mientras la vinculación será en calidad de residente, cuando su estancia en nuestra Comunidad Autónoma supera los tres meses. Por tanto, debería ser obligatoria

\footnotetext{
${ }^{7}$ Con la Ley Orgánica 14/ 2003, de 20 de noviembre, de Reforma de la Ley Orgánica 4/ 2000, de 11 de enero, sobre derechos y libertades de los extranjeros en España y su integración social, modificada por la Ley Orgánica 8/ 2000, de 22 de diciembre; de la Ley 7/ 1985, de 2 de abril, Reguladora de las Bases del Régimen Local; de la Ley 30/ 1992, de 26 de noviembre, de Régimen Jurídico de las Administraciones Públicas y del Procedimiento Administrativo Común, y de la Ley 3/ 1991, de 10 de enero, de Competencia Desleal.
} 
la inscripción en el Padrón municipal del GIC que resida en España con carácter no de "turista", sino de "residente", entendiendo por éste la persona que reside en nuestro país con una duración superior a tres meses, y ello, aunque su permanencia en España al año sea inferior a su permanencia en el país de origen.

En efecto, tal y como está regulado el Padrón Municipal en la LBRL, para poder disfrutar de los derechos y deberes que ostentan el resto de vecinos del municipio en el que se reside, la inscripción de los GIC en el mismo debería configurarse como una obligación legal. E incluso, dado que no es necesario acreditar el empadronamiento para acceder al Registro Central de Extranjeros, debería regularse la posibilidad de un empadronamiento de oficio desde el momento en que la O ficina de Extranjeros inscribe en dicho Registro a un GIC, pues desde ese momento el ciudadano es residente a todos los efectos en España. El proceso sería bastante sencillo, pues la simple comunicación de la inscripción en el Registro Central de Extranjeros por parte de la Oficina de Extranjeros al municipio correspondiente para que éste efectúe la inscripción de oficio en el Padrón Municipal, sería más que suficiente.

Los GIC en Andalucía inscritos en el Padrón de algún municipio andaluz son, junto con el resto de personas inscritas, vecinos del respectivo municipio, condición que se adquiere en el mismo momento de la inscripción y que permite el acceso y ejercicio de una serie de derechos legales que configuran lo que podríamos denominar el Estatuto jurídico de los GIC en Andalucía.

Así, se reconocen con la inscripción en el Padrón municipal los siguientes derechos y deberes (art. 18):

a. Ser elector y elegible de acuerdo con lo dispuesto en la legislación electoral.

b. Participar en la gestión municipal de acuerdo con lo dispuesto en las leyes y, en su caso, cuando la colaboración con carácter voluntario de los vecinos sea interesada por los órganos de gobierno y administración municipal.

c. Utilizar, de acuerdo con su naturaleza, los servicios públicos municipales, y acceder a los aprovechamientos comunales, conforme a las normas aplicables.

d. Contribuir mediante las prestaciones económicas y personales legalmente previstas a la realización de las competencias municipales.

e. Ser informado, previa petición razonada, y dirigir solicitudes a la Administración municipal en relación a todos los expedientes y documentación municipal, de acuerdo con lo previsto en el artículo 105 de la Constitución. 
f. Pedir la consulta popular en los términos previstos en la Ley.

g. Exigir la prestación y, en su caso, el establecimiento del correspondiente servicio público, en el supuesto de constituir una competencia municipal propia de carácter obligatorio.

h. Ejercer la iniciativa popular en los términos previstos en el artículo 70 bis.

i. Aquellos otros derechos y deberes establecidos en las leyes.

Para realizar la inscripción en el Padrón municipal de un GIC sólo son obligatorios los siguientes datos:

a. Nombre y apellidos.

b. Sexo.

c. Domicilio habitual.

d. Nacionalidad.

e. Lugar y fecha de nacimiento.

f. Certificado de inscripción en el Registro Central de Extranjeros o, en su defecto, número del documento acreditativo de la identidad o del pasaporte en vigor expedido por las autoridades del país de procedencia? .

g. Certificado o título escolar o académico que se posea.

\footnotetext{
${ }^{8}$ Según el art. 16.2 de la LBRL.

${ }^{9}$ La exigencia del certificado de inscripción en el Registro Central de Extranjeros deriva de la necesidad de interpretar el primer párrafo del apartado f) del art. 16.2 de la LBRL de conformidad con lo dispuesto en el Real Decreto 240/ 2007, de 16 de febrero, sobre entrada, libre circulación y residencia en España de ciudadanos de los Estados miembros de la Unión Europea y de otros Estados parte en el Acuerdo sobre el Espacio Económico Europeo.

En efecto, el art. 16.2. f) primer párrafo, exige como dato obligatorio para realizar la inscripción en el Padrón municipal, en defecto de pasaporte o documento acreditativo de la identidad, la tarjeta de residencia. Pero la obligación de de poseer la tarjeta de residencia fue parcialmente suprimida por el Real Decreto 178/ 2003, de 14 de febrero, sobre entrada y permanencia en España de nacionales de Estados miembros de la Unión Europea y de otros Estados parte en el Acuerdo sobre el Espacio Económico Europeo, para aquellas personas que siendo titulares de un documento de identidad o un pasaporte nacional válido y en vigor fueran: a) Nacionales de los Estados miembros de la Unión Europea o de otros Estados parte en el Acuerdo sobre el Espacio Económico Europeo, y trabajadores por cuenta propia o ajena, estudiantes o beneficiarios del derecho a residir con carácter permanente; b) Familiares de las personas del párrafo anterior, así como familiares de ciudadanos españoles, y nacionales de algún Estado miembro de la U nión Europea o nacionales de otro de los Estados parte en el Acuerdo sobre el Espacio Económico Europeo; o c) Nacionales de los Estados miembros de la U nión Europea y de otros Estados parte en el Acuerdo sobre el Espacio Económico Europeo, y que trabajen en España manteniendo su residencia en el territorio de alguno de esos Estados y al que regresan todos los días 0 , al menos, una vez por semana. En consecuencia, el que no estuviera incluido en alguno de estos apartados anteriores, estaba obligado a tener la tarjeta de residencia hasta la entrada en vigor del Real Decreto $240 / 2007$, de 16 de febrero, por el que dicha obligación ha quedado totalmente suprimida.
} 
h. Cuantos otros datos puedan ser necesarios para la elaboración del Censo Electoral, siempre que se garantice el respeto a los derechos fundamentales reconocidos en la Constitución.

Estos datos una vez inscritos en el Padrón municipal constituyen para los GIC -igual que para los españoles- prueba de la residencia en el municipio y del domicilio habitual en el mismo ${ }^{10}$. Por tanto, las certificaciones que se expidan sobre los datos que figuran en el Padrón Municipal tendrán carácter de documento público y fehaciente para todos los efectos administrativos. Ahora bien, la inscripción en el Padrón sólo surte efectos durante el tiempo que el sujeto inscrito mantenga su residencia en el municipio ${ }^{11}$.

Es preciso señalar también que con la aprobación del Real Decreto 523/ 2006, de 28 de abril, ha quedado suprimida la exigencia de aportar el certificado de empadronamiento como documento probatorio del domicilio y la residencia, en los procedimientos administrativos de la Administración General del Estado y de sus organismos públicos vinculados o dependientes, pues ahora es la Administración pública la que tiene la carga no sólo de demostrar la veracidad del domicilio del ciudadano a través del Sistema de Verificación de Datos de Residencia ${ }^{12}$, que tiene el mismo valor probatorio que la aportación del certificado de empadronamiento, puesto en marcha con la Orden Ministerial 4008/ 2006, de 27 de diciembre, por la que se establece la configuración, características, requisitos y procedimientos de acceso al Sistema de Verificación de Datos de Residencia, sino también la obligación de solicitar el certificado de empadronamiento al interesado o al Ayuntamiento del municipio correspondiente, si el domicilio no consta en el Sistema de Verificación de Datos de Residencia.

${ }^{10} \mathrm{~A}$ diferencia de los extranjeros no comunitarios, cuya inscripción no constituye prueba de su residencia legal en España ni les atribuye ningún derecho que no les confiera la legislación vigente, especialmente en materia de derechos y libertades de los extranjeros en España (art. 16 de la LBRL).

${ }^{11}$ Los extranjeros no comunitarios sin autorización de residencia permanente están obligados a renovar periódicamente cada dos años la inscripción Si no se procede a tal renovación, el transcurso del plazo señalado será causa para acordar la caducidad de la inscripción. En este caso, la caducidad podrá declararse sin necesidad de audiencia previa del interesado.

${ }^{12}$ Es necesario el consentimiento del interesado para que los datos puedan ser consultados por este sistema por el órgano instructor, debiendo constar dicho consentimiento en la solicitud de iniciación del procedimiento de que se trate $o$ en cualquier otra comunicación posterior. En cualquier caso, si el interesado no prestara su consentimiento deberá aportar el certificado de empadronamiento (art.1.3). 
En definitiva, podemos afirmar que el Padrón municipal no es más que un registro administrativo que refleja las personas que residen en un determinado municipio, otorgando lo que se ha denominado la "vecindad administrativa". Es un registro, por tanto, que sirve para determinar la población del municipio, otorgar la condición de vecino una vez que la inscripción se ha producido, y acreditar la residencia y el domicilio habitual. Además, los datos del padrón sirven para la configuración del censo electoral y para la elaboración de estadísticas oficiales.

No obstante, teniendo en cuenta la diversidad de datos que constan en el padrón, pueden existir otras finalidades municipales, que no siendo incompatibles con las principales antes señaladas, permitan utilizar los datos padronales. Así, por ejemplo, para la prestación de cuántos servicios públicos contribuyan a satisfacer las necesidades del municipio, regulados en los artículos 25 y 26 de la LBRL, cuya utilización puede considerarse una finalidad compatible con la atribuida como principal a dicho registro.

Si el padrón cumple una función estadística de vital importancia para tener un conocimiento fiable de las personas que viven en un municipio, es evidente que la información que contiene además de la relevancia que en sí misma presenta, tiene una gran utilidad para la planificación de los servicios públicos. En efecto, el padrón permite conocer la población de un municipio a partir de la cual es posible programar y organizar los transportes públicos, los servicios educativos, sanitarios, sociales, etc., ya que toda la población, sea nacional o extranjera, acudirá a dichos servicios. Por tanto, la inscripción en el mismo debe considerarse prueba del domicilio donde viven las personas que residen en España, y ello, como garantía para la consecución de un importante efecto jurídico: la posibilidad de disfrutar de los derechos que el ordenamiento jurídico reconoce al efecto.

Sin embargo, a pesar de todo lo expuesto, de la necesidad-obligatoriedad de la inscripción en el Padrón municipal para que los municipios puedan proveer de manera satisfactoria los servicios públicos necesarios para los vecinos de un municipio, lo cierto es que existe un porcentaje importante de GIC residentes en nuestro país que no se registran, y por tanto, no son contabilizados a esos efectos.

Las causas de este subregistro ya fueron puestas de manifiesto por AYLLÓN-DÍAZ GONZÁLEZ en otro trabajo ${ }^{13}$ en el que se destacaban razonesfis-

13 Vid. ECHEZARRETA FERRER, M. El Lugar Europeo de Retiro. Indicadores de excelencia para administrar la gerontoinmigración de ciudadanos de la Unión Europea en municipios españoles. Editorial Comares, Granada, 2005, pág 224. 
cales derivadas de una menor tributación en sus países de origen, pero sobre todo, la falta de arraigo de esta población con el municipio de acogida, pues se caracteriza por ser una población con un estilo de vida itinerante. Aún así, entendemos que la causa principal por la que muchas personas que residen en España no se empadronan es la ausencia de una consecuencia jurídica en caso de incumplimiento de la obligación legal del empadronamiento, lo que unido, en la práctica, a la facilidad de acceso a muchos de los servicios sin exigencia por parte de los poderes públicos del empadronamiento de facto, desincentiva el cumplimiento de dicha obligación. De ahí, que en la práctica los municipios se vean abocados a llevar a cabo estrategias para incentivar el empadronamiento ${ }^{14}$.

Esta realidad del Padrón municipal plantea serios problemas a las Administraciones públicas, pues al desconocer la población real residente en un municipio difícilmente pueden prestarse los servicios públicos de manera adecuada y satisfactoria, más bien al contrario, los servicios se desbordan y son incapaces de atender la demanda de servicios y prestaciones. En suma, no es más que un problema de financiación del coste de los servicios: si no consta, no tributa y si no tributa, no puede recibir. Parece entonces que es totalmente necesaria la adopción de medidas que tiendan a la eliminación de este subregistro de la población GIC que decide residir en nuestro país, máxime cuando estos ciudadanos, por razones de edad, son el colectivo que mayores cuidados y servicios necesita.

Quizás fuera oportuna en estos momentos la reflexión sobre el concepto mismo de residencia como criterio para el acceso a los servicios públicos, y ello, a la vista de la caracterización migratoria de la población objeto de estudio. Claro que si se accede a los servicios con independencia del lugar donde se tiene formalizada la residencia, habrá que establecer algún sistema o instrumento que subsane los problemas financieros, ya sea a través de fórmulas de compensación interterritorial ó aún manteniendo el carácter universal de los servicios públicos, mediante la introducción del pago o copago del servicio por el usuario.

\section{AUSENCIA DE UN SISTEMA SOCIO-SANITARIO EN ESPAÑA}

Analizados los problemas que plantea el acceso al registro municipal de Ios GIC como requisito para obtener la vecindad administrativa necesaria pa-

\footnotetext{
${ }^{14}$ Así, en Torrevieja (Alicante) se conceden pagas extras de 180 euros en verano y navidad a todos los jubilados empadronados en el municipio, y facilita el uso gratuito de los autobuses urbanos; en Torremolinos, Benalmádena, Marbella y Fuengirola (Málaga) se subvencionan tributos y tasas locales a lal población empadronada.
} 
ra el acceso a los servicios públicos, pasamos al análisis de los derechos sociosanitarios que ostentan Ios GIC en Andalucía.

Nuestra Constitución Española reconoce tanto el derecho a la salud como el derecho a los servicios sociales. Así, el artículo 43 recoge el derecho a la protección de la salud con carácter universal. El artículo 41, por su parte, establece un régimen público de Seguridad Social para todos los ciudadanos que les garantice la asistencia y prestaciones sociales suficientes ante situaciones de necesidad; y el artículo 50 reconoce el derecho a la suficiencia económica durante la Tercera Edad, mediante pensiones adecuadas y actualizadas, y a la promoción de su bienestar, mediante un sistema de servicios sociales que atenderán sus problemas específicos de salud, vivienda, cultura y ocio.

Estos derechos constitucionales por su ubicación en el propio texto constitucional -dentro de los "Principios rectores de la política social y económica"- si bien gozan de un valor normativo innegable que vincula a todos los poderes públicos, su verdadero contenido y alcance depende de la concreción que le den las leyes que los desarrollen ${ }^{15}$. Son pues, derechos de configuración legal, lo que obliga a acudir al reparto competencial de materias realizado entre las diferentes Administraciones públicas (Administración General del Estado, Comunidades Autónomas y Administración Local) para determinar sobre quién recae el mandato constitucional de delimitar los anteriores derechos constitucionalmente reconocidos.

De forma muy sistemática, podemos señalar que:

A) En materia sanitaria, al Estado corresponde el establecimiento de las bases y la coordinación de la sanidad (art. 149.1.16a CE) y a las Comunidades Autónomas el desarrollo legislativo y ejecución, en los términos establecidos en sus respectivos Estatutos de Autonomía.

B) En materia de Seguridad Social, el Estado tiene competencia para establecer la legislación básica y el régimen económico (art. 149.1.17a CE) y las Comunidades Autónomas su desarrollo y ejecución, en los términos establecidos en sus respectivos Estatutos de Autonomía.

C) En materia de servicios sociales, la CE no le reserva al Estado competencia, por ello, todas las Comunidades Autónomas han acogido en sus Estatutos de Autonomía la competencia exclusiva sobre la misma, salvo los servicios sociales correspondientes a la Seguridad Social que han seguido el régimen compartido del art. 149.1.17a CE.

${ }^{15}$ Art. 53.2 CE. 
D) En materia de vivienda y urbanismo, turismo y ocio, debemos destacar que las Comunidades Autónomas pueden disponer, en virtud de sus Estatutos, de competencias exclusivas en estas materias.

El ámbito competencial de la Administración Local viene determinado por la LBRL que establece las materias sobre las que el municipio en todo caso ejercerá sus competencias, en los términos de la legislación del Estado y de las Comunidades Autónomas. Así, podemos destacar la competencia de participación en la gestión de la atención primaria de salud y la prestación de los servicios sociales y de promoción y reinserción social ${ }^{16}$. De estas competencias locales en materia sanitaria y social, debe destacarse que la prestación de servicios sociales es un servicio mínimo que está obligado a prestar el municipio con población superior a 20.000 habitantes.

No obstante, el contenido competencial real y efectivo de cada municipio sobre dichas materias queda determinado en las leyes sectoriales, estatales 0 autonómicas, reguladoras de cada sector de la actividad pública, pues el art. 25.3 LBRL establece que "Sólo la L ey determina las competen cias municipales en las materias en unciadas en este artículo, de conformidad con los principios establecidos en el artículo 2". Así, por ejemplo, en materia sanitaria, la Ley General de Sanidad atribuye a los entes locales una serie de responsabilidades mínimas en materia de salud pública ${ }^{17}$, y en materia de asistencia sanitaria, sus competencias quedan reducidas a su participación en la gestión de la atención primaria de salud ${ }^{18}$. Y en materia de servicios sociales, con carácter general, las leyes de las

${ }^{16}$ Art. 25.1 i) y k) de la Ley 7/ 1985, de 2 de abril, de Bases del Régimen Local.

${ }^{17}$ En efecto, el art. 42 de la Ley 14/ 1986, de 25 de abril, General de Sanidad, atribuye a las Corporaciones locales las siguientes competencias:

- control sanitario del medio ambiente: contaminación atmosférica, abastecimiento de aguas, saneamiento de aguas residuales y residuos urbanos e industriales.

- control sanitario de industrias, actividades y servicios, transportes, ruidos y vibraciones.

- control sanitario de edificios y lugares de vivienda y convivencia humana, especialmente de los centros de alimentación, peluquerías, saunas y centros residenciales, escuelas, campamentos turísticos y áreas de actividad físico-deportivas y de recreo.

- control sanitario de la distribución y suministro de alimentos, bebidas y demás productos, directa o indirectamente relacionados con el uso o consumo humanos, así como de sus medios de transporte.

- control sanitario de los cementerios y policía sanitaria mortuaria.

${ }^{18} \mathrm{La}$ Ley General de Sanidad atribuye a las Corporaciones Locales la posibilidad de participar en la gestión y control de las Áreas de Salud (art. 42.2), mediante su participación en el Consejo de Dirección del Área (art. 59), participación que deberá concretar la legislación autonómica. 
Comunidades Autónomas atribuyen a las Corporaciones Locales competencias propias en la programación, la coordinación y la prestación de nivel primario (denominados servicios sociales generales, comunitarios o de atención primaria), que incluyen la información, el diagnóstico, la orientación, así como la atención domiciliaria, los Hogares y Centros de Día, la teleasistencia, etc.

En definitiva, la distribución de competencias entre los poderes públicos pone de manifiesto la ausencia de un sistema público socio-sanitario como tal, y ello a pesar del reconocimiento en el art. 14 de la Ley de Cohesión y Calidad del Sistema Nacional de Salud de la asistencia socio-sanitaria como prestación del Sistema Nacional de Salud ${ }^{19}$. Más bien, existen reconocidos dos sistemas públicos, el sistema sanitario y el sistema de servicios sociales que, aunque obligatoriamente interrelacionados, son muy dispares en su respectiva configuración. Por tanto, tampoco podemos hablar de la existencia de un registro socio-sanitario único que permita a las personas en él inscritas el acceso a la asistencia sanitaria y social. En todo caso, habrá que analizar ambos sistemas públicos por separado para detectar las posibles diffuncionalidades que presentan con respecto a los GIC tanto el registro público sanitario como el de servicios sociales.

\section{EL SISTEMA SANITARIO PÚBLICO Y EL SISTEMA DE SERVI- CIOS SOCIALES}

El sistema sanitario público español se rige por los siguientes principios sustantivos 20 :

${ }^{19}$ El art. 14 establece "La aten ción sociosanitaria compren de el conjunto de cuidados destinados a aque llos enfermos, generalmente crónicos, que por sus especiales características pu eden ben eficiarse de la actuación simultánea y sinérgica de los servicios sanitarios y sociales para aumentar su autonomía, paliar sus limitaciones o sufrimientos y facilitar su rénserción social. En el ámbito sanitario, la atención sociosanitaria se llevará a cabo en los niveles de atención que cada comunidad autónoma determine y en cualquier caso compren de:

a. Los cuidados sanitarios de larga duración.

b. La atención sanitaria a la convalecencia.

c. La rehabilitación en pacientes con déficit funcional recuperable.

La continuidad del servicio será garantizada por los servicios sanitarios y sociales a través de la adecuada coordinación entre las Administraciones públicas correspondientes".

No obstante, debemos destacar que el Real Decreto 1030/ 2006, de 15 de septiembre, por el que se establece la cartera de servicios comunes del Sistema Nacional de Salud y el procedimiento para su actualización, no ha desarrollado la prestación sociosanitaria, con lo que, según lo dispuesto en el art. 8 de la Ley de Cohesión y Calidad del Sistema Nacional de Salud, difícilmente podrá hacerse efectiva dicha prestación.

${ }^{20}$ Véase los arts. 2; 3.2; 18 y 46 e) de la LGS y el art. 2 LCCSNS. 
A) La universalidad de la asisten cia sanitaria pública para todos los ciudadanos en condiciones de igualdad, con independencia de las circunstancias personales o sociales.

B) La equidad en el acceso a las prestaciones sanitarias. El acceso a las prestaciones sanitarias se realizan en condiciones de igualdad efectiva. Se trata de hacer accesibles los recursos sanitarios, de forma que no se produzcan discriminaciones.

C) Financiación pública. El sistema sanitario público se financia en su totalidad de a través del sistema de financiación autonómica vigente. Así, se asegura el derecho de todos a la protección de la salud.

D) La coordinación y, en su caso la integración de todos los recursos sanitarios públicos en un dispositivo único ${ }^{21}$, para asegurar un sistema coherente, armónico y eficaz, sistema que, a su vez, se refuerza con la coordinación y la cooperación de las Administraciones públicas sanitarias para la superación de las desigualdades en salud.

E) La prestación de una aten ción integral a la salud, comprensiva tanto de su promoción como de la prevención de enfermedades, de la asistencia y de la rehabilitación, procurando un alto nivel de calidad.

F) La igualdad de oportunidades y la libre circulación de los profesionales en el conjunto del Sistema Nacional de Salud.

G) La colaboración en tre los servicios sanitarios públicos y privados en la prestación de servicios a los usuarios del Sistema Nacional de Salud.

La acción sanitaria pública es asumida globalmente en el sistema por una misma institución, el Sistema Nacional de Salud descentralizado en los Servicios de Salud de las Comunidades Autónomas (que son los que prestan directamente la asistencia sanitaria a la población). En efecto, el conjunto de todas las estructuras y servicios públicos al servicio de la salud, en suma, el "sistema sanitario público", constituye el Ilamado Sistema Nacional de Salud, formado pues, por los Servicios de Salud de la Administración del Estado y los Servicios de Salud de las Comunidades Autónomas, integrados éstos, a su vez, por todos los centros, servicios y establecimientos de la propia Comunidad Autónoma y los de las Diputaciones, Ayuntamientos y cualesquiera otras Administraciones bajo la responsabilidad de la Comunidad Autónoma22.

\footnotetext{
${ }^{21}$ Como característica fundamental del Sistema Nacional de Salud, según el art. 46 c) de la Ley General de Sanidad.

${ }^{22}$ Arts. 44 y 49 y ss. de la Ley General de Sanidad.
} 
En consecuencia, el Sistema Nacional de Salud constituye una estructura que engloba todas las funciones y prestaciones sanitarias de responsabilidad de los poderes públicos para satisfacer el derecho a la protección de la salud y que articula la coordinación y la integración de todos los servicios públicos de salud.

El sistema de servicios sociales, por su parte, se caracteriza por estar totalmente descentralizado en las Comunidades Autónomas que son las que ejercen las competencias normativas y ejecutivas en la materia, siendo las leyes autonómicas de servicios sociales 0 atención social ${ }^{23}$ las que han ido construyendo el sistema. Además, las prestaciones y servicios sociales que integran este sistema tienen un carácter transversal pues están dirigidas a diferentes colectivos, como menores, mayores, mujeres, inmigrantes, minusválidos, etc.

Pero centrándonos en el colectivo de las personas mayores, que es el que a nosotros nos interesa, las legislaciones autonómicas, ya sea en la normativa general de servicios sociales como en normas específicas especialmente dirigidas a ellos ${ }^{24}$, han puesto en marcha una serie de servicios públicos dirigidos a asistir a las personas mayores en sus necesidades cotidianas básicas y a procurarles una adecuada calidad de vida. Con carácter general, las Administraciones autonómicas prestan a los mayores los siguientes servicios:

23 La legislación autonómica en materia de servicios sociales está formada por la Ley Foral 14/ 1983, de 30 de marzo, de Servicios Sociales de Navarra; Ley 3/ 1986, de 16 de abril, de Servicios Sociales de Castilla-La Mancha; Ley 9/ 1987, de 11 de febrero, de Servicios Sociales de las Islas Baleares; Ley 4/ 1987, de 25 de marzo, de Servicios Sociales de Aragón; Ley 5/ 1987, de 23 de abril, de Servicios Sociales de Extremadura; Ley 9/ 1987, de 28 de abril, de Servicios Sociales de Canarias; Ley 2/ 1988, de 4 de abril, de Servicios Sociales de Andalucía; Ley 18/ 1988, de 28 de diciembre, de Servicios Sociales de Castilla León; Ley 5/ 1992, de 27 de mayo, de Servicios Sociales de Cantabria; Ley 4/ 1993, de 11 de abril, de Servicios Sociales de Galicia; Decreto-Legislativo 17/ 1994, de 16 de noviembre, de Servicios Sociales de Cataluña; Ley 5/ 1996, de 18 de octubre, de Servicios Sociales del País Vasco; Ley 5/ 1997, de 25 de junio, de Servicios Sociales de la Comunidad Valenciana; Ley 1/ 2002, de 1 de marzo, de Servicios Sociales de La Rioja; y Ley 11/ 2003, de 27 de marzo, de Servicios Sociales de la Comunidad de Madrid; Ley 2/ 2003, de 10 de abril, del Sistema de Servicios Sociales de la Región de Murcia; y Ley 1/ 2003, de 24 de diciembre, de Servicios Sociales del Principado de Asturias.

${ }^{24}$ Así, por ejemplo, la Ley $7 /$ 1991, de 5 de abril, de Asistencia y Protección al Anciano de Asturias; Ley 2/ 1994, de 28 de abril, de Asistencia Social Geriátrica de Extremadura; Ley 3/ 1996, de 11 de julio, de Participación de las Personas Mayores y de la Solidaridad entre Generaciones de Canarias; Ley 6/ 1999, de 7 de julio, de Atención y Protección a las Personas Mayores de Andalucía; y Ley 5/ 2003, de 3 de abril, de Atención y Protección de las Personas Mayores de Castilla y León. 
- Servicios públicos de atención al domicilio. Son servicios que facilitan las tareas domésticas cotidianas del mayor en su propio domicilio o que hacen de éste un entorno más adecuado. Así, por ejemplo, los servicios de ayuda a domicilio o las prestaciones económicas para dichas ayudas, los servicios de teleasistencia, los servicios de comida a domicilio o las prestaciones económicas para familias cuidadoras.

- Servicio de atención diurna. Son centros de día ya sea dirigidos específicamente a mayores dependientes físicos o psíquicos, o bien a cualquier mayor, como lugares de convivencia social con otros mayores.

- Servicios de Atención Residencial, en los que el mayor vive y es atendido las 24 horas del día.

- Sistemas Alternativos de Alojamiento como las viviendas públicas tuteladas, los servicios públicos de acogimiento familiar, el alojamiento de jóvenes con personas mayores, o las viviendas compartidas.

Estos servicios prestados desde los sistemas autonómicos de servicios sociales han sido integrados recientemente en el Sistema de Atención de la Dependencia creado con la Ley 39/2006, de 14 de diciembre, de Promoción de la Autonomía Personal y Atención a las personas en situación de dependen$\mathrm{cia}^{25}$, donde las personas mayores, dada la estrecha relación existente entre la edad y la dependencia, ejercen un gran protagonismo.

El Sistema de Atención a la Dependencia tiene como finalidad principal establecer las condiciones básicas que garanticen la igualdad en el ejercicio del derecho subjetivo de ciudadanía a la promoción de la autonomía personal y atención a las personas en situación de dependencia, con la colaboración y participación de todas las Administraciones Públicas, y la garantía por la Administración General del Estado de un contenido mínimo común de derechos para todos los ciudadanos en cualquier parte del territorio del Estado. Para ello, se establece el carácter público de las prestaciones del Sistema de Atención a la Dependencia y la universalidad en el acceso de todas las personas en situación de dependencia, en condiciones de igualdad efectiva y no discriminación.

\footnotetext{
25 Ley estatal dictada al amparo de la competencia exclusiva para la regulación de las condiciones básicas que garanticen la igualdad de todos los españoles en el ejercicio de los derechos y en el cumplimiento de los deberes constitucionales (art. 149.1CE), y con pleno respeto de las competencias que las Comunidades Autónomas hayan asumido en materia de asistencia social en desarrollo del artículo 148.1.20 CE.
} 
Además, existen tres niveles de protección: un nivel de protección mínimo establecido por la Administración General del Estado, según el grado y nivel de la dependencia, como condición básica de garantía del derecho a la promoción de la autonomía personal y atención a la situación de dependencia, que se financia públicamente a través de los Presupuestos Generales del Estado; un segundo nivel de protección que se acuerda entre la Administración General del Estado y la Administración de las Comunidades Autónomas a través de convenios de colaboración y donde se establece la financiación que corresponde a cada una de las Administraciones; y un tercer nivel adicional de protección que puede establecer cada Comunidad Autónoma y con cargo a sus propios presupuestos.

Las prestaciones de atención a la dependencia pueden tener naturaleza de servicios y de prestaciones económicas e irán destinadas, por una parte, a la promoción de la autonomía personal y, por otra, a atender las necesidades de las personas con dificultades para la realización de las actividades básicas de la vida diaria. Pero la financiación de estas prestaciones sociales no es exclusivamente pública pues se establece que los beneficiarios de las prestaciones de dependencia participarán en la financiación de las mismas, según el tipo y coste del servicio y su capacidad económica personal.

\section{REGISTRO SANITARIO}

\section{El acceso a la asistencia sanitaria de los GIC en Andalucía}

Al quedar configurado nuestro sistema sanitario público con carácter universal, parece, en principio, que no puede negarse la asistencia sanitaria al GIC que se encuentre en nuestro país. Efectivamente así es, pues la Ley General de Sanidad reconoce como titulares del derecho a la protección de la salud y a la atención sanitaria a "todos los españoles y los ciu dadanos extran jeros que ten gan establecida su residencia en el territorio nacional" (art. 1.2). La Ley de Cohesión y Calidad del Sistema Nacional de Salud, por su parte, vuelve a delimitar el ámbito subjetivo del derecho a la protección de la salud en su art. 3: "Son titulares de los derechos a la protección de la salud y a la atención sanitaria los siguientes:

a) Todos los españoles y los extranjeros en el territorio nacional en los términos previstos en el artículo 12 de la Ley Orgánica 4/2000, de 11 de en ero, sobre los Derechos y Libertades de los extranjeros y su in tegración social.

b) Los nacionales de los Estados miembros de la Unión Europea que tien en los derechos que resulten del derecho comunitario eu ropeo y de los tratados y convenios que se suscriban por el Estado español y les sean de aplicación. 
c) Los nacionales de Estados no perten ecientes a la Unión Europea que tien en los derechos que les reconozcan las leyes, los tratados y convenios suscritos".

En el mismo sentido, la Ley $2 / 1998$, de 15 de junio, de Salud de Andalucía reconoce, en su artículo 3, el derecho a la asistencia sanitaria a:

1. Los españoles y los extranjeros residentes en cualesquiera de los municipios de Andalucía.

2. Los españoles y extranjeros no residentes en Andalucía, que ten gan establecida su residencia en el territorio nacional, con el alcance determinado por la legislación estatal.

3. Los nacionales de Estados miembros de la Unión Europea tien en los derechos que resulten de la aplicación del derecho comunitario europeo y de los tratados y convenios que se suscriban por el Estado español y les sean de aplicación.

4. Los nacionales de Estados no perten ecientes a la Unión Eu ropea tienen los de rechos que les recon ozcan las leyes, los tratados y convenios su scritos por el Estado español.

5. Sin perjuicio de lo dispuesto en los a partados an teriores de este artículo, se garantizará a todas las personas en Andalucía las prestaciones vitales de emergencia".

En consecuencia, ostentan la titularidad del derecho a la asistencia sanitaria: los españoles-que se encuentren en el territorio nacional, pues si están fuera sólo se les garantiza dicho derecho según lo que las leyes y convenios internacional es establezcan (art. 1.3 LGS); los extranjeros, que acceden a la asistencia sanitaria en las mismas condiciones que los españoles siempre que estén inscritos en el Padrón Municipal, inscripción que no constituye prueba de su residencia legal en España (art. 18.2 LBRL), aunque se les garantiza la asistencia sanitaria de urgencia y a los extranjeros menores de dieciocho años que se encuentren en España y las extranjeras embarazadas durante el embarazo, parto y postparto, se les reconoce el derecho sin necesidad de mayor justificación; los ciudadanos europeos (y por tanto, los GIC), debido al reconocimiento de la libertad de circulación en la U nión Europea ${ }^{26}$ y a la existencia de una política comunitaria sobre salud pública ${ }^{27}$, se garantiza su derecho a la

\footnotetext{
${ }^{26}$ Art. 18 TUE.

${ }^{27}$ Art. 152 TUE.
} 
asistencia sanitaria, en los términos establecidos por el derecho comunitario; y los nacionales no europeos que tienen los derechos reconocidos en las leyes, tratados y convenios.

Reconocido pues el derecho a la asistencia sanitaria de los GIC que se encuentren en Andalucía, existen diferentes vías para el acceso a los servicios sanitarios, en función de la condición en base a la cual el GIC se encuentre en nuestro país, pues la accesibilidad al sistema sanitario varía en función de la condición bajo la que se encuentra: como turista, trabajador ó estudiante (estancia temporal), o como residente (estancia permanente).

En efecto, si la permanencia en Andalucía es temporal, la cobertura sanitaria del GIC se documenta mediante la tarjeta sanitaria europea ${ }^{28}$, documento que viene a sustituir a los formularios E-111 (utilizado por los turistas); E-110 (utilizado por los transportistas internacionales); E-128 (utilizado por los trabajadores desplazados a otro Estado miembro y los estudiantes), y el E-119 (utilizado por los desempleados en busca de trabajo en otro Estado miembro). No obstante, debemos destacar que su entrada en vigor se ha hecho de forma paulatina en tres fases: en primer lugar, desde el 1 de junio de 2004 ( fecha de entrada en vigor) tan sólo fueron sustituidos los formularios de estancia temporal E-111 y E-128; en segundo lugar, hasta finales de 2005, han ido sustituyéndose el resto de formularios de estancia temporal; y por último, en una tercera fase, se preveía que la tarjeta sanitaria europea se convirtiera en un soporte electrónico de grabación y lectura de datos relacionados con el historial médico del paciente (punto 3.3 de la Comunicación de la Comisión relativa a la introducción de la tarjeta sanitaria europea de 17 de febrero de 2003), fase en la que nos encontramos en estos momentos.

Esta tarjeta es individual y certifica el derecho de su titular a recibir las prestaciones sanitarias que sean necesarias desde un punto de vista médico, durante una estancia temporal en cualquiera de los países integrantes de la Unión Europea (Alemania, Austria, Bélgica, República Checa, Chipre, Dinamarca, Eslovaquia, Eslovenia, Estonia, Finlandia, Francia, Grecia, H ungría, Irlanda, Italia, Letonia, Lituania, Luxemburgo, Malta, Países Bajos, Polonia, Portugal, Reino Unido, Suecia), del Espacio Económico Europeo (Islandia,

${ }^{28}$ Decisiones 189/2003/ CE, 190/2003/ CE y 191/ 2003/ CE, de 18 de junio de 2003, dirigidas a sustituir por una tarjeta sanitaria europea los formularios necesarios para la aplicación de los Reglamentos (CE) 1408/ 71 y (CE) 574/ 72, en lo que respecta al acceso a la asistencia sanitaria durante una estancia temporal en un Estado miembro distinto del Estado competente o de residencia; relativa a las características técnicas de la tarjeta sanitaria europea, y relativa a la sustitución de los formularios E 111 y E 111 B por la tarjeta sanitaria europea (DOCE L 276). 
Liechtenstein, Noruega) y Suiza, teniendo en cuenta la naturaleza de las prestaciones y la duración prevista de la estancia. Este derecho deriva del Reglamento Comunitario 1408/71, del Consejo de 14 de junio de 1971, relativo a la aplicación de los regímenes de seguridad social a los trabajadores por cuenta ajena, a los trabajadores por cuenta propia y a los miembros de sus familias que se desplacen dentro de la Comunidad, y el Reglamento (CEE) 574/ 72 de 21 de marzo de 1972, que recoge las modalidades de aplicación. Ambos Reglamentos comunitarios derogados por el Reglamento (CEE) 883/2004, del Parlamento Europeo y del Consejo, de 29 de abril de 2004, sobre la coordinación de los sistemas de seguridad social.

Es importante destacar que la asistencia sanitaria a la que se puede acceder con la tarjeta sanitaria europea ${ }^{29}$, si bien se recibe en igualdad de condiciones con los asegurados del país al que se desplaza, sólo comprende la atención médica necesaria como consecuencia de la estancia temporal en un Estado miembro, es decir, cubre una asistencia temporal, por tanto, no es válida si el motivo del desplazamiento a otro Estado es recibir un tratamiento médico específico, una asistencia programada -en cuyo caso, es necesaria la previa autorización de la institución competente ${ }^{30}$ (formulario E-112) -, ni si se produce un cambio del lugar de residencia.

${ }^{29} \mathrm{El}$ órgano competente para su emisión en España son los Centros de Atención e Información de la Seguridad Social (CAISS) del Instituto Nacional de la Seguridad Social.

${ }^{30}$ Así se recoge en el art. 20 del Reglamento (CEE) 883/ 2004, del Parlamento Europeo y del Consejo, de 29 de abril de 2004, sobre la coordinación de los sistemas de seguridad social, que establece:

"1. Salvo disposición en contrario del presente Reglamento, la persona asegurada que se desplace a otro Estado miembro para recibir prestaciones en especie du rante su estancia deberá solicitar la autorización de la institución competente.

2. La persona asegurada autorizada por la institución competentea desplazarse a otro Estado miembro para recibir en éste un tratamiento adecuado a su estado de salud se ben eficiará de las prestaciones en especie facilitadas, por cuenta de la institución competente, por la institución del lugar de estancia, según las disposiciones de la legislación que ésta última aplique, como si estuviera asegurada en virtud de dicha legislación. La autorización deberá ser concedida cuando el tratamiento de que se trate figure entre las prestaciones pre vistas por la legislación del Estado miembro en que resida el interesado y cuando, habida cuenta de su estado de salud en ese momento y de la evolución probable de la enfermedad, dicho tratamiento no pueda serle dispensado en un plazo justificable desde el punto de vista médico.

3. Los apartados 1 y 2 se aplicarán por analogía a los miembros de la familia de una persona asegurada.

4. Cuando los miembros de la familia de una persona asegurada residan en un Estado miembro distinto de Estado miembro de residencia de la persona asegu rada, y dicho Estado miembro aplique un sistema de reembolso basado en cantidades a tanto alzado, el coste de las prestaciones en especie indicadas en el apartado 2 será asumido por la institución del lugar de residencia de los miembros de la familia. En este caso y a efectos de apartado 1, se considerará que la institución competente es la institución del lugar de residencia de los miembros de la familia". 
Pero si la estancia del GIC en Andalucía tiene carácter permanente, o mejor dicho, no es una estancia, sino una residencia y, como ocurre en nuestro objeto de estudio, se trata de pensionistas que han ejercido una actividad de trabajador por cuenta ajena o por cuenta propia en un Estado miembro de la Unión Europea (o del Espacio Económico Europeo), y vienen a residir a nuestra Comunidad Autónoma - pues, si vienen durante un período inferior a tres meses, se les considera turistas y tienen derecho a la tarjeta sanitaria europea-, necesitan para poder acceder a los servicios sanitarios en las mismas condiciones que los españoles, estar en posesión del formulario E-121 (documento que acredita a los titulares de pensión o renta y a sus familias su inscripción en el registro de beneficiarios de prestaciones sanitarias que se desplazan a un Estado miembro pero reciben su pensión de otro Estado miembro).

Dicha formalidad documental deriva, al no existir una cotización en el Estado miembro de acogida, de la necesidad de acreditar que durante su residencia en otro Estado miembro, no lleguen a constituir una carga para la asistencia social de dicho Estado, y dispongan de un seguro de enfermedad que cubra todos los riesgos en el Estado miembro de acogida31.

\footnotetext{
${ }^{31}$ Así lo exige la legislación comunitaria. La ya derogada Directiva 90/ 365/ CEE del Consejo, de 28 de junio de 1990, relativa al derecho de residencia de los trabajadores por cuenta ajena 0 por cuenta propia que hayan dejado de ejercer su actividad profesional establecía que los Estados miembros concederían el derecho de residencia a todos los nacionales de los Estados miembros que hayan desempeñado en la Comunidad una actividad como trabajadores por cuenta ajena o por cuenta propia, así como a los miembros de su familia, siempre que disfrutaran de una pensión de invalidez, de jubilación anticipada o de vejez, o de un subsidio por accidente de trabajo o enfermedad profesional de nivel suficiente para que, durante su estancia, no lleguen a constituir una carga para la asistencia social del Estado miembro de acogida, y dispongan de un seguro de enfermedad que cubra todos los riesgos en el Estado miembro de acogida.

En el mismo sentido, la actual Directiva 2004/ 38/ CEE del Parlamento Europeo y del Consejo, de 29 de abril de 2004, relativa al derecho de los ciudadanos de la Unión y de los miembros de sus familias a circular y residir libremente en el territorio de los Estados miembros -transpuesta a nuestro ordenamiento interno a través del Real Decreto 240/ 2007, de 16 de febrero-reconoce que todo ciudadano de la U nión tiene derecho de residencia en el territorio de otro Estado miembro por un período superior a tres meses si dispone, para sí y los miembros de su familia, de recursos suficientes para no convertirse en una carga para la asistencia social del Estado miembro de acogida durante su período de residencia, así como de un seguro de enfermedad que cubra todos los riesgos en el Estado miembro de acogida (art. 7.1.b)). Lo que deba entenderse por recursos suficientes a estos efectos, viene también determinado por la propia Directiva que establece en su art. 8.4 que "L os Estados miembros no podrán establecer un importe fijo correspondiente a lo que consideran "recursos suficientes", sino que tendrán que tener en cuenta la situación personal del interesado. En cualquier caso, dicho importe no superará el nivel de recursos por debajo del cual el Estado miembro de acogida puede conceder asisten cia social a sus nacionales 0 , cuando no pueda aplicarse tal criterio, el nivel de la pensión mínima de seguridad social pagada por el Estado miembro de acogida".
} 
Por tanto, cuando un GIC retorne a Andalucía siendo titular de una pensión a cargo del país de origen que le dé derecho a las prestaciones sanitarias, tendrá cubiertas, él y sus familiares, las citadas prestaciones una vez que fije su residencia en la Comunidad Autónoma. Para ello, deberá acudir a la oficina del Instituto Nacional de la Seguridad Social (INSS) correspondiente a su lugar de residencia, presentando el formulario E-121, que le será proporcionado por la institución competente extranjera a efectos del Seguro de enfermedad. U na vez efectuados los trámites oportunos, la oficina del IN SS Ie facilitará el documento de asistencia previsto para los pensionistas de la Seguridad Social española. Ese documento expedido por el Instituto Nacional de la Seguridad Social (órgano competente para acreditar o reconocer el derecho a la asistencia sanitaria) tiene validez en todo el territorio nacional, y por tanto ante la Administración sanitaria autonómica andaluza, que es la competente para expedir la tarjeta sanitaria individual ${ }^{32}$ y poder así acceder a los servicios sanitarios en las mismas condiciones que los andaluces ${ }^{33}$.

Sin embargo, si se trata de un pensionista no comunitario, procedente de algún país con el que España tiene suscrito convenio de Seguridad Social que incluye la prestación de asistencia sanitaria en residencia habitual, dicho pensionista, que percibe una pensión a cargo de su país que le da derecho a las prestaciones sanitarias, para tener cubiertas, él y sus familiares a cargo, las citadas prestaciones una vez que fije su residencia en Andalucía, deberá acudir a la oficina del INSS correspondiente a su lugar de residencia presentando, según sea su país de procedencia, el siguiente formulario emitido por el organismo competente extranjero a efectos del Seguro de enfermedad:

- Andorra: Formulario E/ AND-734

- Brasil: Formulario EB-2 con validez definitiva ${ }^{35}$

- Chile: Formulario E/ CHL-0936

\footnotetext{
32 Vid. Real Decreto 183/ 2004, de 30 de enero, por el que se regula la tarjeta sanitaria individual.

${ }^{33}$ Así deriva de la Resolución de 21 de noviembre de 2005, del Instituto Nacional de la Seguridad Social, por la que se establecen los modelos de documento acreditativo del derecho a la asistencia sanitaria de los pensionistas de la Seguridad Social y otros beneficiarios.

${ }^{34}$ Legislación: Convenio hispano andorrano de Seguridad Social de 14 de abril de 1978.

35 Legislación: Convenio hispanobrasileño de Seguridad Social de 16 de mayo de 1991.

${ }^{36}$ Legislación: Convenio hispano chileno de Seguridad Social de 9 de marzo de 1997.
} 
- Ecuador: Formulario EE-637

- Marruecos: Formulario EM-738

La Dirección Provincial o Centro de Atención e Información del INSS (CAISS) le facilitará el documento de asistencia sanitaria previsto para los pensionistas de la Seguridad Social, en caso de proceder de Andorra, Brasil, Chile o Marruecos. Pero si procede de Ecuador, con el formulario y una fotocopia, podrán acudir a los centros sanitarios de la Seguridad Social española.

Y si se trata de un pensionista procedente de Suiza o de otro país con el que España tiene convenio de Seguridad Social que no incluye la exportación de prestaciones sanitarias en residencia habitual, así como países con los que España no tiene suscrito convenios en materia de asistencia sanitaria ${ }^{39}$, los emigrantes titulares de una pensión o que hayan sido beneficiarios de rentas o cantidades a tanto alzado sustitutivas de dicha pensión a cargo de la Seguridad Social suiza o de otros países con los que no exista convenio en materia de asistencia sanitaria, si al trasladar su residencia a España no tienen cubierta dicha prestación, podrán suscribir un Convenio Especial de asistencia sanitaria con la Seguridad Social española para ser beneficiarios de la misma. La cobertura sanitaria se hará extensiva a los familiares que vivan a expensas del titular y no tengan derecho por otro título a las prestaciones de asistencia sanitaria.

Para suscribir dicho Convenio Especial tendrá que formularse la solicitud ante la Dirección Provincial de la Tesorería General de la Seguridad Social del lugar de residencia, en el modelo oficial, acompañada del documento que acredite la percepción de la pensión de la Seguridad Social suiza o de otro país, debiendo abonarse mensualmente por el interesado la cuota fijada al efecto. En caso de que el interesado tenga familiares a su cargo, deberá unirse la documentación acreditativa de tal extremo. Además, los pensionistas habrán de probar la fecha de su retorno al territorio nacional y suscribir el convenio dentro de los 180 días naturales siguientes a la indicada fecha.

${ }^{37}$ Legislación: Convenio hispano ecuatoriano de Seguridad Social de 1 de abril de 1960.

${ }^{38}$ Legislación: Convenio hispano marroquí de Seguridad Social de 6 de noviembre de 1979.

${ }^{39}$ Legislación: Orden de 5 de mayo de 1980. Orden de 18 de febrero de 1981 (BOE de 26 de febrero).

Resolución 21 de abril de 1997 Secretaría de Estado de la Seguridad Social (BOE de 5 de mayo). 
2. Deficiencias jurídicas en la prestación de asistencia sanitaria a los ciudadanos europeos retirados

Centrándonos en los GIC, la principal consecuencia del reconocimiento del derecho a la asistencia sanitaria en nuestro país en las mismas condiciones que los españoles es la perdida de cualquier derecho en materia sanitaria en su país de origen. Al emitirse el formulario E-121 el país de origen está reconociendo, por un lado, que su nacional va a recibir todas las prestaciones sanitarias necesarias para garantizar su derecho a la protección de la salud en el nuevo país de residencia, y por otro, que los gastos sanitarios originados por su nacional corren a su cargo, pues es en el país de origen donde ha cotizado el nacional y al que corresponde pagar la pensión por jubilación y todas las prestaciones públicas a las que tenga derecho. Ello significa que si el nacional vuelve a su país de origen y durante su estancia allí necesita atención sanitaria, dicha estancia será como turista español y necesitará la tarjeta sanitaria europea emitida por España.

Es precisamente esa pérdida de derechos sanitarios en el país de origen lo que origina que muchos GIC residentes en España no cumplan con las formalidades administrativas expuestas en el apartado anterior.

En definitiva, en la práctica nos encontramos con un porcentaje nada despreciable de GIC que a pesar de tener su residencia en nuestro país, no formalizan su situación administrativa para poder acceder a las prestaciones sanitarias. Ello implica que durante su residencia en España, y en concreto en nuestra Comunidad Autónoma, acceden a todos los recursos sanitarios que necesitan por vía de urgencia, pues como es sabido, las prestaciones vitales de emergencia se garantizan a todos los ciudadanos, sean éstos españoles o extranjeros, tal y como se establece en el art. 3 de la Ley 2/ 1998, de 15 de junio, de Salud de Andalucía. Máxime cuando la asistencia sanitaria de urgencia incluye no sólo la atención de la urgencia de que se trate, sino todas las prestaciones necesarias hasta el alta del paciente.

Esta situación está provocando, como no podía ser de otra forma, un desmesurado aumento del gasto sanitario en nuestro país, pues los servicios sanitarios a los que acceden éstos GIC, al ser asistencia sanitaria de urgencia, no son compensados ni por el país de origen -que no tiene constancia de su acceso a la sanidad española al no haber solicitado su nacional el formulario E-121-, ni por el propio usuario de los servicios sanitarios, al estar configurada nuestra sanidad como un derecho universal y financiado públicamente. Tampoco debe olvidarse que muchos GIC, aunque residentes en Andalucía, 
poseen la tarjeta sanitaria europea ${ }^{40}$, lo que les permite acceder a los servicios sanitarios de forma ordinaria sin acudir por la vía de urgencias. Pero en este caso, el problema se produce por la mala gestión de la Administración pública sanitaria que no solicita la tarjeta sanitaria europea, y por tanto, no factura el gasto sanitario producido.

Este crecimiento del gasto es aún mayor en las zonas costeras que son las que soportan una mayor demanda de extranjeros. En Andalucía, el gasto sanitario y farmacéutico que supone para el Servicio Andaluz de Salud la asistencia sanitaria a los extranjeros se ha desbordado en losúltimos años. Según datos del H ospital de la Costa del Sol de Marbella, en el mes de junio de 2006 casi tres de cada diez pacientes hospitalizados eran extranjeros, así como el $25,8 \%$ de los usuarios atendidos en consultas externas y el $15,4 \%$ de las personas que pasaron por U rgencias (datos muy superiores con respecto a los meses de verano del año anterior -2005-que finalizó con casi 65.000 extranjeros atendidos). El Servicio de Traducción e Interpretación del Hospital Clínico Universitario de Málaga, por su parte, está atendiendo a una media de 50 pacientes extranjeros diarios ${ }^{41}$.

Para determinar las causas de este problema, debemos distinguir si un GIC se encuentra en Andalucía con la condición de turista o con la condición de residente. En el primer caso, como ya hemos expuesto, el GIC turista para acceder a la asistencia sanitaria necesita estar en posesión de la tarjeta sanitaria europea, pues la presentación de la misma en el centro sanitario donde se recibe la asistencia sanitaria permite la facturación de los costes generados. La compensación de los gastos originados por la prestación de asistencia sanitaria se efectúa a través del Fondo de Cohesión Sanitaria, regulado por el RD $1207 / 2006$, de 20 de octubre, y creado en el año $2002^{42}$ con la finalidad de evitar desigualdades territoriales en el acceso a los servicios sanitarios.

En concreto, se compensa a las Comunidades Autónomas, con cargo al Fondo de cohesión sanitaria, los gastos originados por la prestación de asistencia sanitaria a:

${ }^{40}$ Vienen a Andalucía con la TSE y como tiene, con carácter regla general, un periodo de validez de 1 año, y de cuatro en caso de pensionistas, desde la fecha de expedición, cuando vuelven a su país, la renuevan, lo que hace que aunque de facto sean residentes en Andalucía, para la Administración sanitaria son turistas.

${ }^{41}$ Véase noticia publicada en Diario Málaga -Costa del Sol- el 5 de diciembre de 2006 bajo el titular "El turismo de salud dispara el gasto sanitario y farmacéutico".

42 Por el RD1247/ 2002, de 3 de diciembre, por el que se regula la gestión del Fondo de cohesión sanitaria. 
a) Pacientes residentes en España derivados entre comunidades autónomas.

b) Asegurados desplazad os a España en estancia temporal, con derecho a asistencia a cargo de otro Estado, que pertenezcan a países de la U nión Europea o a otros con los cuales España tenga firmados acuerdos bilaterales en esta materia.

c) Pacientes residentes en España derivados entre comunidades autónomas para su atención en centros, servicios y unidades de referencia del Sistema Nacional de Salud.

En lo que a nosotros nos interesa, se compensa la atención sanitaria a ciudadanos desplazados temporalmente a España, respecto a los que, en virtud de la aplicación de los Reglamentos (CEE) n 1408/ 71 del Consejo, de 14 de junio de 1971, y n 574/ 72 del Consejo, de 21 de marzo de 1972, o de los convenios suscritos por España en materia de Seguridad Social, el derecho a la asistencia sanitaria sea por cuenta de una institución de otro Estado, siempre que dichos ciudadanos hayan entrado y permanezcan legalmente en España y la asistencia prestada esté cubierta por los citados convenios internacionales ${ }^{43}$.

A estos efectos, resulta interesante señalar los criterios de distribución de la compensación del Fondo a las comunidades autónomas por la asistencia sanitaria prestada a desplazados a España en estancia temporal. En primer lugar, la cuantía global de la compensación es igual al saldo neto positivo resultante, en el ámbito nacional, entre el importe recaudado por España por la prestación de asistencia sanitaria a ciudadanos asegurados de otros Estados y el pagado por la asistencia sanitaria dispensada, en otros Estados, a ciudadanos asegurados en España, al amparo de la normativa internacional.

La distribución entre comunidades autónomas del saldo neto determinado en el apartado anterior se realizará tomando como base la facturación que cada Comunidad Autónoma presente por dicho concepto al Instituto Nacional de la Seguridad Social y sea validada técnicamente por éste ${ }^{44}$, y la que este organismo reciba de otros Estados por la asistencia sanitaria prestada a ase-

${ }^{43}$ Art. 5 RD 1207/ 2006, de 20 de octubre.

44 Dicha factura es transmitida y gestionada mediante los sistemas de información de facturación internacional del Instituto Nacional de la Seguridad Social puestos a disposición de las Comunidades Autónomas por el citado Instituto. Con este sistema informatizado de datos se elimina del proceso de compensación de los gastos al INSS autonómico, ya que los servicios de salud autonómicos facturan directamente al INSS central. 
gurados de la comunidad autónoma desplazados en el extranjero. El reparto se realiza entre aquellas Comunidades Autónomas que presenten un saldo positivo entre las facturas emitidas a ciudadanos asegurados en otro Estado y las cargadas por otros países a asegurados de la comunidad autónoma desplazados en el extranjero y será proporcional a los saldos netos de facturación registrados para cada comunidad autónoma.

Sin embargo, este sistema de compensación a las Comunidades Autónomas por la asistencia sanitaria prestada a los extranjeros comunitarios y no comunitarios que se encuentra en España en estancia temporal, presenta algunos inconvenientes. Por ejemplo, en la práctica, no todos los pacientes acuden portando la tarjeta sanitaria europea, la mayoría acceden por los servicios de urgencias sin presentar dicho documento y sin que él mismo le sea exigido por el Servicio Autonómico de Salud. Además, hay determinadas prestaciones (intervenciones quirúrgicas o tratamientos) que no se pueden facturar al país de origen porque no se contemplan dentro de la cartera básica de servicios del país en cuestión. Ello unido a que el reintegro a las Comunidades Autónomas se efectúa con base al criterio de población efectivamente censada -criterio que no coincide con la población real que soportan las Comunidades Autónomas, sobre todo aquéllas que reciben a un mayor número de extranjeros como Andalucía o Valencia-y la ausencia de una compensación real de los gastos a los servicios sanitarios autonómicos, son factores que coadyuvan a ese aumento desmesurado del gasto sanitario del que venimos hablando.

El sistema de reintegro de la asistencia sanitaria prestada a los GIC residentes en nuestro país, por su parte, se realiza de forma bien diferente. Como los GIC deben transferir sus derechos de pensionista (a través del formulario E-121), son los países de origen los que pagan una cuota anual de 2.092 euros a España para que reciban la asistencia sanitaria y farmacéutica en las mismas condiciones que un ciudadano español. Hasta el año 2006 las Comunidades Autónomas no recibían compensación al guna por la prestación de asistencia sanitaria a los jubilados europeos residentes, pues la cuantía era facturada por el Instituto N acional de la Seguridad Social. No obstante, desde ese año las Comunidades Autónomas han comenzado a recibir el pago de dichas cantidades en función de los documentos E-121 que cada Comunidad acredite, y ello en virtud del acuerdo alcanzado en la II Conferencia de Presidentes de las Comunidades Autónomas celebrada el 10 de septiembre de 2005. El déficit en las economías autonómicas se repite también en el caso de los pensionistas europeos residentes en España, pues el coste de los servicios sanitarios que demandan los jubilados europeos residentes que no transfieren sus derechos de pensionista es asumido en su totalidad por los servicios autonómicos de salud. 
3. Dicotomía jurídica entre la libertad comunitaria de circulación de personas y la competencia exclusiva de los Estados miembros para organizar y regular los sistemas sanitarios nacionales

La progresiva eliminación de las barreras y restricciones al ejercicio efectivo del derecho de los ciudadanos europeos a la libre circulación y prestación de servicios dentro de la Unión Europea constituye, sin duda, uno de los mayores éxitos alcanzados. En efecto, la U nión garantiza en su interior las libertades fundamentales de circulación de personas, servicios, mercancías y capitales, así como la de establecimiento ${ }^{45}$. Por ello, se reconoce a toda persona que tenga la nacionalidad de un Estado miembro, la ciudadanía europea y el derecho de circular y residir libremente en el territorio de la Comunidad ${ }^{46}$.

Sobre la base de este reconocimiento comunitario, la primera manifestación del derecho a la salud desde una perspectiva individual la encontramos en la Carta de Derechos Fundamentales de la Unión Europea de 2000. Su artículo 35 dispone "toda persona tiene derecho a la preven ción sanitaria y a ben eficiarse de la aten ción sanitaria conforme a las con diciones establecidas en las disposiciones nacionales. Al definirse y ejecu tarse todas las políticas y acciones de la Unión se garantizará un alto nivel de protección de la salud humana" 47 . Se recoge, por tanto, el derecho a la asistencia sanitaria, pero con carácter de "mínimos" y supeditando su contenido efectivo a la regulación interna de cada Estado miembro. La novedad de la Carta de Derechos Fundamentales consistía en otorgar a éste y al resto de los derechos civiles, políticos, económicos y sociales reconocidos, el carácter de derechos fundamentales europeos. Sin embargo, y en contra de las previsiones iniciales, la citada Carta no fue incorporada al Tratado de Niza del 2000, quedando, en consecuencia, con un valor meramente programático hasta su incorporación como Parte II en el Tratado de Roma por el

\footnotetext{
${ }^{45}$ Art. I-4 del Tratado de Roma por el que se establece una Constitución para Europa, aún no en vigor.

${ }^{46} \mathrm{Art}$. I-10 del Tratado de Roma por el que se establece una Constitución para Europa, aún no en vigor.

${ }^{47}$ El origen de este precepto lo encontramos en el artículo 11 de la Carta Social Europea de 1961 donde ya se recogía el derecho a la protección de la salud. En concreto, dicho precepto establece que para garantizar el derecho a la protección de la salud, las Partes Contratantes se comprometen a adoptar, directamente 0 en cooperación con organizaciones públicas o privadas, medidas adecuadas para, entre otros fines: eliminar, en lo posible, las causas de una salud deficiente; establecer servicios educacionales y de consulta dirigidos a la mejora de la salud y a estimar el sentido de responsabilidad individual en lo concerniente a la misma, y prevenir, en lo posible las enfermedades epidémicas, endémicas y otras.
} 
que se establece una Constitución para Europa, de 29 de octubre de 2004. Como es sabido, este Tratado no ha llegado a entrar en vigor por la falta de ratificación por algunos Estados, como Francia y Holanda, lo que está planteando la necesidad de reformar el Tratado de Roma. Por tanto, sólo si en el Tratado de Reforma, que próximamente elaborará la Conferencia Intergubernamental, se incluye la citada Carta de Derechos Fundamentales, una vez producida la ratificación por todos los Estados miembros, formará parte del Derecho originario y será norma a la que se someterán el resto de normas comunitarias.

Aún así, el Tratado de Roma por el que se establece una Constitución para Europa dedica el artículo 95 al derecho a la protección de la salud: "T oda persona tiene derecho a acceder a la preven ción sanitaria y a ben eficiarse de la aten ción sanitaria en las condiciones establecidas por las legislaciones y prácticas nacionales. Al definirse y ejecutarse todas las políticas y acciones dela Unión se garantizará un al to nivel elevado de protección de la salud humana".

No obstante, debemos señalar que al definir las políticas y acciones comunitarias en el ámbito de la salud, la U nión se centra de manera exclusiva en la salud pública, ámbito en el que tiene competencia para realizar una acción de apoyo, coordinación o complemento, y sobre el que la Comunidad Europea viene desarrollando una política efectiva desde el año $1992^{48}$. Al contrario de lo que ocurre en el ámbito de la asistencia sanitaria pública donde apenas existen políticas o acciones comunitarias, y ello, porque la asistencia sanitaria es responsabilidad exclusiva de los Estados miembros. En este sentido, la determinación de los sujetos con derecho a la asistencia sanitaria, las prestaciones sanitarias, la organización y provisión de los servicios sanitarios, la financiación, etc., son cuestiones que deben abordar las legislaciones nacionales. Ello explica la ausencia de un Derecho derivado -reglamentos y directivas-que regule la asistencia sanitaria o establezca la armonización de legislaciones nacionales sobre la misma. Estamos, por tanto, todavía lejos de alcanzar una concepción integral de la sanidad-comprensiva tanto de la salud pública como de la asistencia sanitaria- a nivel comunitario.

${ }^{48}$ Con la puesta en marcha, con el Tratado de Maastricht de 1992, de ocho Programas de Salud Pública (que recogían actuaciones en materia de cáncer, SIDA, toxicomanía, promoción de la salud, vigilancia de la salud, enfermedades poco comunes, enfermedades relacionadas con la contaminación y hemoderivados) con el objeto de establecer un marco de acción que permitiera responder adecuadamente a las nuevas obligaciones derivadas del Tratado, las cuales hacían referencia a aspectos como la contribución a la consecución de un alto nivel de protección de la salud, el fomento de la cooperación entre los Estados miembros, la prevención de las enfermedades y la adopción de medidas de fomento. 


\subsection{Libre circulación de pacientes en el espacio comunitario europeo}

Aunque no exista a nivel comunitario una concreción jurídica del derecho a la asistencia sanitaria dentro de la protección del derecho a la salud, si que se ha realizado un desarrollo tangencial de la misma en la regulación comunitaria de la Seguridad Social de los trabajadores. En concreto, en el Reglamento (CE) 1408/ 71, de 14 de junio, relativo a la aplicación de los regímenes de seguridad social a los trabajadores por cuenta ajena y a sus familias que se desplazan dentro de la Comunidad -derogado por el Reglamento (CE) 883/ 2004, del Parlamento Europeo y del Consejo, de 29 de abril de 2004, sobre la coordinación de los sistemas de Seguridad Social-Éste se dictó con el objeto de eliminar los obstáculos para la libre circulación de trabajadores derivados de la existencia de una pluralidad de legislaciones nacionales en materia de Seguridad Social, cuya aplicación podría suponer la pérdida de derechos para los trabajadores que se desplazan, por motivos laborales, a otro Estado miembro. Para ello, se establecen una serie de disposiciones que, entre otras previsiones, regulan las distintas prestaciones de Seguridad Social, y por tanto, también regula la asistencia sanitaria en casos de enfermedad y maternidad. Además, con la introducción de la tarjeta sanitaria europea no sólo se ha reconocido el derecho sino que se ha intentando eliminar o simplificar los trámites y formalidades para hacerlo efectivo.

No cabe duda de que el fundamento de esta regulación es garantizar la libre circulación de personas, pero sólo, y esto es lo relevante a efectos sanitarios, durante una estancia temporal en otro Estado, ya sea por motivos laborales, turismo o estudios. No se ha reparado en que la libre circulación de los ciudadanos europeos no sólo consiste en viajes turísticos o laborales de corta duración, sino también en la movilidad no turística como es el derecho a residir en otro Estado, en cuyo caso, se exige, tal y como hemos expuesto, que los pensionistas demuestren que no van a producir ningún gasto para el sistema social de acogida. En el caso español se exige a los europeos jubilados que quieren disfrutar de una estancia superior a tres meses que trasladen sus derechos de asistencia sanitaria desde su país de origen a España.

La exigencia de estos requisitos supone una limitación a la libre circulación de los individuos económicamente no activos, fundamentalmente desde el punto de vista sanitario, pues al trasladar sus derechos de pensionista pierden todos los derechos sanitarios en el país de origen.

Todo ello es consecuencia de la importante contradicción jurídica que existe en materia de asistencia sanitaria a nivel comunitario, lo que produce 
una serie de efectos jurídicos muy relevantes. Me estoy refieriendo a que al mismo tiempo que se establece que la acción comunitaria debe respetar plenamente las responsabilidades de los Estados miembros en la organización y provisión de los servicios sanitarios y la atención médica, excluyendo cualquier armonización de la legislación y normativas nacionales, se consagra la integración económica en un Mercado Ú nico Europeo. Esto significa que es enormemente difícil separar la integración económica europea de las responsabilidades puramente nacionales en materia de sanidad, ya que el sistema sanitario también constituye una parte fundamental de la economía. Es imposible regular uno de ellos sin afectar al otro. Y es que la libre circulación de personas, bienes, servicios y capitales significa también el libre movimiento de profesionales sanitarios, de usuarios, de medicamentos, de tecnología, de servicios sanitarios, etc. De ahí, que la relación entre la U nión Europea y los sistemas sanitarios se esté convirtiendo en una cuestión cada vez más compleja.

Además, estamos asistiendo en los últimos años al reconocimiento jurisprudencial de una protección comunitaria de quienes se desplazan entre diversos Estados miembros para recibir atención médica en un país distinto al de su residencia. Es lo que se ha empezado a denominar "libre circulación de pacientes" o "turismo sanitario". Para entender el alcance y las consecuencias de este nuevo concepto es preciso distinguir las distintas situaciones que podrían englobarse en la expresión libre circulación de pacientes. Y ello porque podemos encontrarnos con:

a) Una persona que se desplaza a otro Estado miembro distinto del de su residencia para recibir asistencia sanitaria a cargo de sus propios recursoseconómicos. Esta situación responde a la libre prestación de servicios que incluye, además del desplazamiento de empresas y profesionales prestadores de servicios a países distintos de aquel en el que están establecidos, el desplazamiento de los usuarios o beneficiarios de los correspondientes servicios, entre los que se encuentra los servicios sanitarios.

b) Una persona que se desplaza a otro Estado por motivos de trabajo; viaje de turismo; estudios; cuestiones personales o familiares, etc., y se produce una situación -por enfermedad o accidente- que requiere una atención médica inmediata. Estos supuestos están previstos por el Derecho Comunitario -Reglamento (CE) 1408/ 71, 14 de junio de 1971-y responden, más que a la libre circulación de pacientes, a la libre circulación de personas, pues el objeto del desplazamiento no es recibir asistencia sanitaria.

c) Una persona que se desplaza a un Estado miembro distinto del de su residencia para recibir asistencia sanitaria como beneficiario del sis- 
tema de asistencia sanitaria pública, es decir, con cargo a su sistema público de cobertura sanitaria (Sistema Nacional de Salud o Seguridad Social). Este es el supuesto tipo que responde al concepto de libre circulación de pacientes.

La libre circulación de pacientes así entendida afecta, sin duda, a la configuración del derecho a la asistencia sanitaria y supondría amparar dentro del mismo la financiación pública de la asistencia sanitaria prestada en otro país comunitario cuando el motivo del desplazamiento ha sido el deseo de superar las carencias o insuficiencias de los tratamientos accesibles en el Estado de residencia o para recibir una asistencia de mayor calidad o más rápida que la disponible en su país.

Esta afirmación, contraria a las previsiones del Tratado en materia sanitaria que establece la competencia exclusiva de los Estados miembros en la organización y provisión de sus servicios sanitarios, y por ende, en financiación pública, está adquiriendo mayor fuerza, en los últimos años, a raíz de una serie de pronunciamientos del Tribunal de Justicia de las Comunidades Europeas que reconocen una protección comunitaria de quienes se desplazan entre diversos Estados miembros para recibir atención médica en un país distinto al de su residencia.

En efecto, la doctrina jurisprudencial favorable a la aplicación de la libre prestación de servicios a las regulaciones nacionales sobre la asistencia sanitaria deriva de dos sentencias: Ia Sentencia Kohll, de 28 de abril de 1998 y la Sentencia Smits y Peerbooms, de 12 de julio de 2001. En ellas, el Tribunal viene a establecer que aunque los Estados miembros sean los únicos competentes para organizar sus sistemas sanitarios, ello no significa que sus ordenaciones en materia de asistencia sanitaria pública no deban respetar el principio comunitario de libre prestación de servicios, pues el hecho de que un tratamiento médico sea financiado públicamente no elimina su carácter de actividad económica. Ahora bien, el que los sistemas sanitarios nacionales exijan una autorización previa para permitir la asistencia sanitaria en el extranjero no supone una restricción al principio de libre circulación de servicios siempre que se justifique por razones imperiosas de interés general -entiende el Tribunal que en la asistencia hospitalaria el interés general queda justificado por las necesidades de planificación sanitaria-. Además, para que un ciudadano europeo pueda recibir asistencia sanitaria en otro Estado miembro es preciso que tenga derecho a la prestación concreta en el Estado del que procede, es decir, que la misma esté en el catálogo de prestaciones de su sistema sanitario, y que tenga el carácter de prestación necesaria en el sentido de que 
la autorización para someterse a tratamiento en otro Estado miembro sólo puede ser denegada cuando un tratamiento idéntico o que presenta el mismo grado de eficacia para el paciente pueda conseguirse en tiempo acudiendo a un centro o establecimiento del Estado en el que reside.

No cabe duda de que estos pronunciamientos jurisprudenciales establecen una nueva perspectiva de la incidencia directa de las libertades fundamentales comunitarias sobre los sistemas nacionales de provisión de asistencia sanitaria pública.

No obstante, a pesar de que los sistemas sanitarios nacionales cada vez están más interrelacionados a nivel comunitario, lo que supone para el ciudadano europeo un avance en materia de movilidad en términos de libre circulación de pacientes, sobre todo desde los pronunciamientos del Tribunal de Justicia de las Comunidades Europeas, el reconocimiento de una protección comunitaria de quienes se desplazan entre diversos Estados miembros para recibir atención médica en un país distinto al de su residencia, no implica, por el momento, la necesidad de modificar los sistemas nacionales de asistencia sanitaria, tan sólo supone respetar las reglas de la libre circulación de personas, pues, a partir de dichas sentencias, la asistencia sanitaria se considera como un servicio a efectos del Derecho Comunitario.

Por tanto, podemos afirmar que la reciente doctrina jurisprudencial no afecta a la configuración de los sistemas sanitarios nacionales. No deducir esta conclusión de la misma supone un grave error que lleva a sostener afirmaciones tales como el reconocimiento de un sistema sanitario europeo. Entendemos que la diversidad de los modos de financiación y de organización sanitaria, característica fundamental de Europa, unida a la ausencia de un desarrollo significativo de la asistencia sanitaria que deben recibir los ciudadanos para hacer efectivo el derecho a la protección de la salud a nivel comunitario, sitúan todavía lejano el momento en el que podamos hablar de un sistema sanitario europeo único.

Además, impulsar la creación de un sistema sanitario europeo requiere de un amplio debate, en el que con la participación de todos los sujetos afectados -autoridades, responsables, profesionales y usuarios del sistema-, se adopte una posición común sobre algunas cuestiones que, a priori, encierran enormes dificultades. Entre ellas, sería primordial determinar el modelo sanitario aplicable y decantarse bien por un Sistema Nacional de Salud, o bien por un Sistema de Seguridad Social, con todas las reticencias que, sin duda, pro- 
vocaría en los Estados miembros, además de las dificultades para su aplicación efectiva. Igualmente, sería fundamental delimitar el modelo de financiación -pública o privada-; la provisión - pública o privada-; el catálogo mínimo de prestaciones; el modelo de calidad asistencial; etc. Cuestiones que, como se puede imaginar, no presentan una solución factible a primera vista. En consecuencia, la coexistencia en estos momentos de diferentes ordenaciones nacionales sobre la asistencia sanitaria hace enormemente difícil poder hablar, en estos momentos, de un sistema sanitario europeo único y un catálogo europeo básico de prestaciones sanitarias.

No obstante, aunque la integración de los servicios sanitarios a escala europea no sea factible, no debemos perder de vista la realidad a la que nos enfrentamos: la total integración de los sistemas sanitarios nacionales en el Mercado Único Europeo, con todo lo que ello implica de reconocimiento y respeto de las libertades comunitarias fundamentales.

\section{REGISTROS SOCIALES}

\section{El acceso a los servicios sociales de los GIC en Andalucía}

El reconocimiento del derecho de acceso a los servicios sociales a todas las personas que residan en un determinado municipio podemos afirmar que constituye la regla general en el reconocimiento de este derecho tanto por las leyes de las Comunidades Autónomas en la materia como por la Ley 39/2006, de 14 de diciembre, de Promoción de la Autonomía Personal y Atención a las personas en situación de dependencia.

Así, el art. 5 de la Ley de Promoción de la Autonomía Personal y Atención a las personas en situación de dependencia establece:

"1. Son titulares de los derechos establecidos en la misma los españoles que cumplan los siguientes requisitos:

a) Encontrarse en situación de dependen cia en alguno de los grados establecidos.

b) Para los menores de 3 años se estará a lo dispuesto en la disposición adicional decimotercera.

c) Residir en territorio español y haberlo hecho durante cinco años, de los cuales dos deberán ser inmediatamente anteriores a la fecha de presentación de la solicitud. Para los men ores de cinco años el periodo de residencia se exigirá a quien ejerza su guarda y custodia.

2. Las personas que, reuniendo los requisitos anteriores, carezca de la nacionalidad española se regirán por lo establecido en la Ley O rgánica 4/2000, de 11 de enero, 
sobre derechos y libertades de los extranjeros en España y su integración social ${ }^{49}$, en los tratados internacionales y en los convenios que se establezcan con el país de origen".

Nuestra Comunidad Autónoma, por su parte, en materia de personas mayores, reconoce el derecho de acceso a las prestaciones y servicios previstos en la misma a los extranjeros con "residencia" en cualquier municipio de Andalucía (art. 2.1b) de la Ley 6/ 1999, de 7 de julio, de Atención y Protección a las Personas Mayores de Andalucía). El Decreto 76/2001, de 13 de marzo, por el que se regula la concesión y uso de la Tarjeta Andalucía Junta Sesenta y Cinco, que permite a sus titulares acceder a las prestaciones y servicios que se establezcan al efecto en el ámbito de los servicios sociales, exige a los beneficiarios, además de tener 65 años de edad, el empadronamiento en cualquier municipio de Andalucía (art. 2).

En consecuencia, los GIC que se encuentran en Andalucía con carácter temporal (menos de tres meses), al no ser residentes, no tienen derecho de acceso a nuestro sistema de servicios sociales por no estar empadronados; mientras que el GIC residente, siempre que se encuentre empadronado, tiene derecho a disfrutar de todas las prestaciones sociales en igualdad de condiciones que un español. Por tanto, y a diferencia de lo que ocurre en el ámbito sanitario, en el que como hemos vistos, los GIC pueden acceder a los servicios y prestaciones sanitarias, por la vía de urgencia, sin necesidad de cumplir ninguna formalidad registral, pues la asistencia sanitaria se caracteriza por su universalidad formal, lo que implica que todos tienen derecho a ella sin necesidad de formalidad alguna, para el acceso a las prestaciones y servicios sociales, el GIC debe estar inscrito en el Padrón municipal del municipio en el que reside.

Las prestaciones y servicios que oferta el Sistema para la Autonomía y Atención a la dependencia, creado por la Ley 39/2006, de 14 de diciembre, que no son otras que las que ya venían prestando los servicios sociales autonómicos pero que ahora quedan integrados en un dispositivo único -la red de servicios del sistema para la autonomía y atención a la dependencia-, se inspiran en una serie de principios básicos como son el carácter público de las prestaciones; la universalidad en el acceso; una atención integral e integrada;

\footnotetext{
${ }^{49} \mathrm{El}$ art.14 de la Ley Orgánica 4/ 2000, de 11 enero, por la que se regulan los derechos y libertades de los extranjeros en España y su integración social, reconoce en cuanto a los servicios y prestaciones sociales, que los extranjeros residentes tienen derecho tanto a los servicios generales y básicos como a los específicos, en las mismas condiciones que los españoles.
} 
la transversalidad de las políticas de atención; la colaboración de los servicios sociales y sanitarios en la prestación de los servicios; la participación de la iniciativa privada y del tercer sector en los servicios y prestaciones de promoción de la autonomía personal y atención a la situación de dependencia; la cooperación interadministrativa; y la integración de las prestaciones en las redes de servicios sociales de las Comunidades Autónomas, en el ámbito de las competencias que tienen asumidas, y el reconocimiento y garantía de su oferta mediante centros y servicios públicos o privados concertados.

A pesar de ello, se trata de un sistema público al que tienen derecho a acceder en condiciones de igualdad, con independencia del lugar del territorio español en el que se resida, sólo aquellas personas en situación de dependencia que sean titulares del derecho, es decir, aquellas que residan en el territorio español durante cinco años, de los cuales dos deberán ser inmediatamente anteriores a la fecha de presentación de la solicitud. Esto también resulta aplicable a los GIC en Andalucía, pues la Ley 4/ 2000, de 11 de enero, recoge en su art. 14 que el acceso a los servicios y prestaciones sociales, tanto generales y básicos como específicos se hará en las mismas condiciones que los españoles. Por tanto, el requisito de la residencia -justificado en Andalucía con el empadronamiento- es el único que determina el acceso o no al sistema de servicios sociales.

Este requisito de la residencia en Andalucía durante cinco años, de los cuales dos deberán ser inmediatamente anteriores a la fecha de presentación de la solicitud, que deben cumplir los GIC para acceder al sistema de prestaciones sociales de la dependencia, puede plantear algún problema jurídico si atendemos a lo previsto en el artículo 48 de la Ley 8/ 2006, de 24 de octubre, por la que se aprueba el Estatuto de los Andaluces en el mundo, en el que se establece que los andaluces retornados que cumplan con los requisitos exigidos, podrán acceder a las prestaciones educativas, sanitario-asistenciales y de asistencia social, sin necesidad de acreditar un período de residencia previa en Andalucía, siempre que:

a) Hayan residido fuera de Andalucía durante un período, continuado e inmediatamente anterior al retorno, igual o mayor al de residencia previa exigido a los no emigrantes, en función de los programas que arbitren al efecto las diferentes Administraciones Públicas andaluzas.

b) Hayan fijado su residencia en Andalucía tras el retorno.

En efecto, si al andaluz que ha residido fuera de Andalucía no se le exige la acreditación de la residencia durante cinco años para acceder a las presta- 
ciones de dependencia, exigir dicho requisito al GIC podría vulnerar no sólo la libertad comunitaria de circulación y residencia, sino incluso lo previsto en la legislación de extranjería que impone que el acceso a los servicios y prestaciones sociales se realice en las mismas condiciones que los españoles.

\section{La Atención a la Dependencia de los GIC en Andalucía}

La protección de la situación de dependencia por parte del Sistema para la Autonomía y Atención a la Dependencia se presta de acuerdo con los siguientes niveles:

19) Un nivel de protección mínimo, establecido por la Administración General del Estado, destinado a garantizar un mínimo de protección para cada uno de los beneficiarios del Sistema, según el grado y nivel de su dependencia.

2ㅇ) Un nivel de protección que se acuerde entre la Administración General del Estado y la Administración de cada una de las Comunidades Autónomas a través de los correspondientes convenios.

3o) Un nivel adicional de protección que pueda establecer cada Comunidad Autónoma.

La Ley 39/ 2006 garantiza que las personas en situación de dependencia tendrán derecho, con independencia del lugar del territorio del Estado español donde residan, a acceder, en condiciones de igualdad, a las prestaciones y servicios siguientes:

A) Al Catálogo de servicios sociales de promoción de la autonomía personal y de atención a la dependencia que se recoge en el art. 15 de la Ley ${ }^{50}$.

${ }^{50}$ El Catálogo de servicios comprende los servicios sociales de promoción de la autonomía personal y de atención a la dependencia:

a) Los servicios de prevención de las situaciones de dependencia y los de promoción de la autonomía personal.

b) Servicio de Teleasistencia.

c) Servicio de Ayuda a domicilio:

(i) Atención de las necesidades del hogar.

(ii) Cuidados personales.

d) Servicio de Centro de Día y de Noche:

(i) Centro de Día para mayores.

(ii) Centro de Día para menores de 65 años.

(iii) Centro de Día de atención especializada.

(iv) Centro de Noche. 
B) Prestaciones económicas de las siguientes modalidades:

- Prestación económica vinculada. Esta prestación irá destinada a la cobertura de los gastos del servicio previsto en su programa individual de atención, cuando no sea posible la atención mediante un servicio de los anteriores.

- Prestación económica para cuidados familiares. El beneficiario podrá, excepcionalmente, recibir una prestación económica para ser atendido por cuidadores familiares, siempre que se den condiciones adecuadas de convivencia y de habitabilidad de la vivienda y así lo establezca su programa individual de atención. Esta prestación supone un apoyo directo a las familias que desean atender a sus mayores en el medio familiar.

- Prestación económica de asistencia personal. Ésta tiene como finalidad la promoción de la autonomía de las personas con gran dependencia, menores de sesenta y años. Por tanto, queda fuera de nuestro objeto de estudio.

C) Ayudas económicas para facilitar la autonomía personal. Estas ayudas irán destinadas a apoyar a la persona con ayudas técnicas o instrumentos necesarios para el normal desenvolvimiento de su vida ordinaria y a facilitar la eliminación de barreras arquitectónicas y adaptaciones en el hogar que contribuyan a mejorar su capacidad de desplazamiento en la vivienda.

La situación de dependencia se clasifica en los siguientes grados:

A) Grado I. Dependencia moderada: Cuando la persona necesita ayuda para realizar varias actividades básicas de la vida diaria, al menos una vez al día.

B) Grado II. Dependencia severa: Cuando la persona necesita ayuda para realizar varias actividades básicas de la vida diaria dos o tres veces al día, pero no requiere la presencia permanente de un cuidador.

C) Grado III. Gran dependencia: Cuando la persona necesita ayuda para realizar varias actividades básicas de la vida diaria varias veces al día y por su pérdida total de autonomía mental o física, necesita la presencia indispensable y continúa de otra persona.

e) Servicio de Atención Residencial:

(i) Residencia de personas mayores en situación de dependencia.

(ii) Centro de atención a personas en situación de dependencia, en razón de los distintos tipos de discapacidad. 
Cada uno de estos grados de dependencia se divide en dos niveles, en función de la autonomía de la personas y de la intensidad del cuidado que requiere. El grado y nivel de dependencia de cada persona corresponde determinarlo a las Comunidades Autónomas mediante la aplicación del baremo que ha acordado el Consejo Territorial del Sistema Nacional de Dependencia y que ha sido aprobado por el Gobierno mediante Real Decreto 504/ 2007, de 20 de abril ${ }^{51}$. Ello es así porque las prestaciones y servicios se prestan desde las respectivas Comunidades Autónomas a través de la Red de Servicios Sociales autonómicas.

En cuanto a la financiación del Sistema, éste se financia públicamente por el Estado en el primer nivel de protección; por el Estado y las Comunidades Autónomas en el segundo nivel; y por las Comunidades Autónomas exclusivamente en el tercer nivel adicional de protección, sólo en función de tipo y coste del servicio y la capacidad económica del beneficiario, que se calcula sobre el conjunto de sus rentas y patrimonio.

En consecuencia, los servicios sociales aunque tengan carácter público, no son de financiación exclusivamente pública como ocurre en el ámbito sanitario, ni gozan del carácter de gratuidad. Es un sistema de financiación mixta - pública y privada-en el que además participa el usuario en el coste del servicio.

Ello podría explica la ausencia de un sistema de compensación por los costes de los servicios social es prestad os a los ciudadanos europeos, pues al residir de manera efectiva en nuestro país y estar registrados en un Padrón Municipal tienen asegurado el derecho y disfrute de tales prestaciones. No obstante, debe señalarse que la jurisprudencia del TJCE ha interpretado que, aunque no se mencionen como rama aparte, ni se definan por la dificultad de llegar a una definición común aceptada por todos los Estados miembros, hay que considerar que las prestaciones de dependencia están incluidas en el campo de aplicación del Reglamento CEE 1408/ 71 -y actualmente también, del Reglamento CE 883/ 2004.

En este sentido, en la Sentencia de 5 de marzo de 1998, asunto C-160/ 96, M. Molenaar, el TJCE consagra, en relación con las prestaciones de dependencia, que son prestaciones, en especie o en metálico, que complementan las del seguro de enfermedad. Y que, por ello, las primeras se conceden confor-

${ }^{51}$ Así se establece en el art. 27 de la Ley 39/ 2006. 
me a la legislación de país en el que se reside; pero dado que las económicas son abonadas por la institución del país de aseguramiento o afiliación, que, en consecuencia, son exportables. I gualmente, en la Sentencia de 8 de marzo de 2001, en el asunto C-215/99, F. Jauch, el Tribunal consideró que la asignación de asistencia austríaca, abonable a las personas que residen en Austria para proporcionar ayuda y que puedan vivir de forma autónoma, a pesar de estar incluida en el Anexo II bis del Reglamento CEE 1408/ 71 (lo que la excluiría de la exportación) fue, no obstante, a juicio del TJCE, considerada una prestación de naturaleza idéntica a las prestaciones alemanas a que se refirió en la sentencia Molenaar y, como tal, estimó que era una prestación en metálico que completa las prestaciones del seguro de enfermedad con el fin de mejorar el estado de salud y las condiciones de vida de las personas necesitadas de cuidados especiales. Añadiendo que, a tales efectos, es irrelevante que la asignación de asistencia sea o no de carácter contributivo. Y consideró que, a consecuencia de lo anterior y de su calificación con prestación en metálico de enfermedad, debería abonarse aunque el interesado no resida en Austria.

Esta jurisprudencia del TJCE se consolida con la Sentencia de 21 de febrero de 2006, asunto C-286/ 03, S. H osse v. Land Salzburg, en la que el TJCE ha interpretado que "una prestación podrá ser considerada una prestación de se guridad social en la medida en que se conceda a sus ben eficiarios, al margen de cualquier apreciación individual y discrecional de las necesidades personales, en función de una situación legalmente definida y en la medida en que la prestación se refiera a alguno de los riesgos expresamente en umerados del art. 4.1 del Reglamento 1408/71". En concreto afirma que "las prestaciones, concedidas de modo objetivo, en función de una situación legalmente definida con el fin de mejorar el estado de salud y las condiciones de vida de las personas depen dientes están fundamentalmente destinadas a completar las prestaciones del segu ro de en fermedad y deben ser con sideradas prestaciones de enfermedad".

Esta doctrina jurisprudencia pone de manifiesto la necesidad de regular los criterios para compensar los gastos a la red de servicios andaluces del sistema para la autonomía y atención a la dependencia prestadores de la asistencia -económica o en especie-a las personas dependientes, por el país de origen de los GIC. El establecimiento de un sistema de compensación de gastos de los servicios y prestaciones sociales entre los Estados, similar al que existe en el ámbito sanitario, a pesar de las disfunciones prácticas que presenta, es fundamental para evitar un problema aún mayor al que tendremos que hacer frente en un futuro próximo en caso contrario, pues ello supondrá un notable aumento del gasto público social. 


\section{VII.FALTA DE COORDINACIÓN ENTRE LOS SERVICIOS SANITA- RIOS Y SOCIALES}

La atención socio-sanitaria a las personas dependientes es un factor clave en la cobertura de las necesidades que este colectivo de personas precisa. Para ello, resulta fundamental que las prestaciones sociales y sanitarias estén coordinadas.

Lo cierto es, sin embargo, que la Ley 39/2006, de 14 de diciembre, de Promoción de la Autonomía Personal y Atención a las personas en situación de dependencia, diferencia claramente la cobertura de los ámbitos social y sanitario. Así, cuando el art. 15 regula el catálogo de servicios del Sistema para la Autonomía y Atención a la Dependencia, lo hace señalando que se establecen estos servicios, "sin perjuicio de las prestaciones sociosanitarias que se regulan en la Ley de Cohesión y Calidad de Sistema Nacional de Salud".

Efectivamente, la Ley de Cohesión y Calidad del Sistema Nacional de Salud consagra en su art. 14 la atención sociosanitaria como una prestación sanitaria básica. Sin embargo, dicha afirmación legal carece de virtualidad práctica alguna, pues el Real Decreto 1030/ 2006, de 15 de septiembre, por el que se establece la cartera de servicios comunes del Sistema Nacional de Salud, a través de la cual se hacen efectivas las prestaciones sanitarias, no regulado la prestación sociosanitaria.

Por tanto, resulta fundamental para que el Sistema de Autonomía y Atención a la Dependencia se convierta en un sistema público socio-sanitario capaz de ofrecer y prestar todos los servicios asistenciales y económicos necesarios para que las personas dependientes consigan mayores cotas de autonomía, que se diseñen los instrumentos y mecanismos para que la coordinación y cooperación entre los servicios sociales y sanitarios sea real y efectiva.

Logro éste que además facilitaría el sistema de compensación de los gastos por los servicios prestados a los GIC en Andalucía, pues no habría que establecer ningún sistema de compensación diferente al que ya existe en el ámbito sanitario. Así, cuando los GIC trasfieran sus derechos de pensionista a nuestro país (a través del formulario E121), la cuota anual que pagan los países de origen a España cubriría no la asistencia sanitaria y farmacéutica como ocurre hasta el momento, sino los costes por la asistencia sociosanitaria que sus nacionales reciban de las instituciones públicas andaluzas. 


\section{Conclusiones}

1. La legislación nacional sobre el Padrón municipal (Ley $7 /$ 1985, de 2 de abril, de Bases del Régimen Local) está pensada para los ciudadanos españoles que residen en un municipio del territorio nacional, no para los GIC residentes en España, cuya movilidad al país de origen determinado tiempo al año es una realidad. Por ello, resulta fundamental adaptar la legislación nacional a las reglamentaciones de la U nión Europea.

2. Aunque los GIC residentes están obligados a inscribirse en el Padrón del municipio en el que residan, no existe consecuencia jurídica ante el incumplimiento de dicha obligación, lo que además se ve reforzado cuando en la práctica, para el acceso a algunos servicios y el ejercicio de al gunos derechos no se exige por las autoridades públicas el certificado de empadronamiento.

Por ello, se debería exigir el empadronamiento para todo aquel ciudadano europeo o del Espacio Económico Europeo que resida en nuestro país más de tres meses, de conformidad con las previsiones del Real Decreto 240/ 2007, de 16 de febrero, sobre entrada, libre circulación y residencia en España de ciudadanos de los Estados miembros de la U nión Europea y de otros Estados parte en el Acuerdo sobre el Espacio Económico Europeo. En él como hemos visto, se parte de una idea fundamental: la persona que viene a nuestro país en calidad de turista debe permanecer con carácter temporal durante un periodo que no puede ser superior a tres meses. Por tanto, toda estancia superior a tres meses otorga al ciudadano europeo, y por tanto al GIC, el carácter de residente en España.

Una posible propuesta para regular y adaptar lo previsto en el apartado anterior, podría ser la configuración del empadronamiento de oficio cuando el GIC acude a la O ficina de Extranjeros a inscribirse en el Registro Central de Extranjeros. Propuesta que entendemos sería muy fácil de llevar a cabo, a la vista del Real Decreto 523/ 2006, de 28 de abril, que suprime la exigencia de aportar el certificado de empadronamiento como documento probatorio del domicilio y la residencia, en los procedimientos administrativos de la Administración General del Estado y de sus organismos públicos vinculados o dependientes. Como sabemos, ahora es la Administración pública la que tiene la carga no sólo de demostrar la veracidad del domicilio del ciudadano a través del Sistema de Verificación de Datos de Residencia, sino también la obligación de solicitar el certificado de empadronamiento al interesado o al Ayuntamiento del municipio correspondiente, si el domicilio no consta en el Sistema de Verificación de Datos de Residencia. Así, cuando la O ficina de Extran- 
jeros antes de inscribir a la persona en el Registro Central de Extranjeros acuda a dicho Sistema para verificar los datos aportados sobre el domicilio, si el GIC no está empadronado, bastaría con una notificación al Ayuntamiento correspondiente, para que éste realice la inscripción de oficio en el Padrón municipal.

3. Existe descoordinación y falta de información entre las Administraciones Públicas con competencias sobre los registros públicos-administrativos. Creemos que deben establecerse los mecanismos precisos para garantizar una eficaz interrelación entre los poderes públicos, y ello, en aras de poder verificar que el GIC reside de facto en nuestro país, y es un ciudadano que efectivamente tiene derecho a acceder a los servicios y prestaciones que nuestro país ofrece.

4. A pesar del reconocimiento expreso del nuevo Estatuto de Autonomía de Andalucía de los derechos socio-sanitarios de las personas mayores residentes en Andalucía y de la trasposición a nuestro ordenamiento jurídico de las Directivas comunitarias sobre la libre circulación de los ciudadanos europeos, a través del Real Decreto 240/ 2007, de 16 de febrero, lo cierto es que, en la práctica, existe una descoordinación entre el reconocimiento del derecho comunitario de libertad de residencia a los GIC y las formalidades registrales que deben cumplir para tener garantizado el derecho de acceso a las prestaciones socio-sanitarias en la Comunidad Autónoma de Andalucía.

5. En materia sanitaria, porque la principal consecuencia del reconocimiento del derecho a la asistencia sanitaria en nuestro país en las mismas condiciones que los españoles a los GIC es la perdida de cualquier derecho en materia sanitaria en su país de origen. Y es precisamente esa pérdida de derechos sanitarios en el país de origen lo que origina que muchos $\mathrm{GIC}$ residentes en España no cumplan con las formalidades administrativas exigidas. Ello implica que durante su residencia en España, y en concreto en nuestra Comunidad Autónoma, acceden a todos los recursos sanitarios que necesitan por vía de urgencia, pues como es sabido, las prestaciones vitales de emergencia se garantizan a todos los ciudadanos, sean éstos españoles o extranjeros, máxime cuando la asistencia sanitaria de urgencia incluye no sólo la atención de la urgencia de que se trate, sino todas las prestaciones necesarias hasta el alta del paciente.

Esta situación está provocando un desmesurado aumento del gasto sanitario en nuestra Comunidad Autónoma, pues los servicios sanitarios a los que acceden los GIC, al ser asistencia sanitaria de urgencia, no son compensados 
ni por el país de origen -que no tiene constancia de su acceso a la sanidad española al no haber solicitado su nacional el formulario E-121-, ni por el propio usuario de los servicios sanitarios, al estar configurada nuestra sanidad como un derecho universal y financiado públicamente. En otras ocasiones, muchos GIC, aunque residentes en Andalucía, poseen la tarjeta sanitaria europea, lo que les permite acceder a los servicios sanitarios de forma ordinaria sin acudir por la vía de urgencias. Pero en este caso, el problema se produce por la mala gestión de la Administración pública sanitaria que no solicita la tarjeta sanitaria europea, y por tanto, no factura el gasto sanitario producido.

6. En materia social, para el acceso a las prestaciones de dependencia el legislador estatal y andaluz exige como requisito para el acceso a las mismas la acreditación de la residencia mediante el empadronamiento en un municipio. Por tanto, el GIC en Andalucía debe estar empadronado en algún municipio andaluz para tener derecho a las prestaciones de dependencia. Sin embargo, los problemas se plantean al no existir mecanismo alguno de compensación de los costes sociales por los países de origen.

7. Por todo lo anterior, resulta fundamental establecer los mecanismos necesarios para garantizar de manera efectiva la libre circulación de los ciudadanos europeos, y por ende de los GIC. Ello implica, de un lado, facilitar desde cada legislación nacional, al ser competencia exclusiva de los Estados, el acceso a los servicios socio-sanitarios que cada Estado proporciona a sus nacionales y, de otro lado, un refuerzo comunitario de la cooperación interestatal al objeto de la compensación de los gastos que ocasionen.

8. La principal iniciativa pública que debe llevarse a cabo al efecto es la dotar de eficacia jurídica la obligatoriedad de inscripción en los registros público-administrativos como legitimación del derecho de acceso a la asistencia socio-sanitaria. En este sentido, es preciso tomar conciencia de la importancia de exigir la tarjeta sanitaria europea a los GIC turistas, o la tarjeta sanitaria proporcionada por el INSS y que acredita el traspaso de los derechos de pensionista a los GIC residentes, cuando acceden a los servicios sanitarios. Pues de lo contrario, no podrán facturarse los gastos a su país de origen.

9. En cuanto a los problemas que se plantean en el sistema de reintegro de los gastos socio-sanitarios, debiera regularse la creación de un Fondo de cohesión socio-sanitaria a nivel europeo que se encargue de la gestión y distribución de la compensación entre Estados por los costes socio-sanitarios, pues parece que la tendencia de la última jurisprudencia del TJCE es entender que las prestaciones de dependencia, concedidas de modo objetivo, en 
función de una situación legalmente definida con el fin de mejorar el estado de salud y las condiciones de vida de las personas dependientes, están fundamentalmente destinadas a completar las prestaciones del seguro de enfermedad y deben ser consideradas prestaciones de enfermedad. Y dicho sistema de compensación debería incluir, y esto es importante, la posibilidad de facturar al país de origen por la prestación a sus nacionales de servicios socio-sanitarios con independencia de que éstos consten o no en sus carteras básicas de salud. Y ello, porque entiendo muy difícil -dado el estado actual de la distribución de competencias entre la UE y los Estados miembros- el establecimiento de una cartera de servicios socio-sanitarios básicos común a toda la UE.

10. Aunque para que ello sea posible, debiera comenzarse por introducir desde los poderes públicos las medidas necesarias para conseguir una coordinación real entre los servicios sociales y sanitarios, pues sólo así podremos hablar del acceso de los GIC a una atención gerontológica integral.

BIBLIOGRAFÍA:

ABEL-SMITH, "El precio de los servicios sanitarios", Cuadernos de Salud Pública dela OM S, núm. 17.

AGUADO I CUDOLÁ, V., “Hacia una nueva población municipal: el padrón como instrumento para la realización de políticas públicas y para el ejercicio de derechos de españoles y extranjeros", Anuario del Gobierno Local, núm. 1, 2003, págs. 195-240.

ALAMEDA CASTILLO, M.T., Régimen jurídico de las personas con discapacidad en España y en la Unión Europea. Granada: Comares, 2006.

ÁLVAREZ VÉLEZ, M.I., “El principio de igualdad y el derecho de asistencia sanitaria", Revista de Administración Sanitaria, Vol. VI, núm. 22, 2002.

APARICIO TOVAR, J., La Seguridad Social y la protección de la salud. Ed. Civitas, Madrid, 1989.

BARCELÓN COBEDO, S.; QUINTERO LIMA, M. "Las situaciones de dependencia personal como nueva contingencia protegida por el sistema de protección social". Revista del M inisterio de Trabajo y A suntos Sociales. 2006. n. 60, p.13-33. 
BELTRÁN AGUIRRE, J.L. "Prestaciones sanitarias del Sistema Nacional de Salud: aspectos jurídicos". Revista de Derecho y Salud, Vol. 2, núm. 2, julio-diciembre, 1994.

BELTRÁN AGUIRRE, J.L. "Prestaciones sanitarias y autonomías territoriales: cuestiones en torno a la igualdad". Revista de Derecho y Salud, Vol. 10, núm. 1, enero-junio, 2002.

CASADO, D. "Expectativas de las personas mayores respecto a la Ley de dependencia". Revista de M inisterio de Trabajo y Asuntos Sociales. 2006, n. 60, p. $149-165$.

CASADO, D. “La protección social de la dependencia”. Revista española del tercer sector. 2006, n. 3, p. 1-227.

DIZY MENÉDEZ, Dolores (ed.). Las personas mayores en situación de dependencia: propuesta de un modelo protector mixto yestimación del coste de aseguramiento en España. Madrid: Edad \& Vida, 2006.

ECHEZARRETA FERRER, M. El Lugar Europeo de Retiro. Indicadores de excelencia para administrar la gerontoinmigración de ciudadanos de la Unión Europea en municipios españoles. Editorial Comares, Granada, 2005.

ELOLA SOM OZA, J., Política Sanitaria española, Ed. Díaz de Santos, 2001.

ENGELS, Dietrich. "La situación del cuidado asistencial en Alemania en los ciudadanos mayores". Revista de servicios sociales y política social. 2006, n. 74, p. 157-171.

GARCÍA VALVERDE, M.D.; MALDONADO MOLINA, J.A. "La protección de la tercera edad, su tratamiento en la Constitución europea". Revista del Ministerio de Trabajo y Asuntos Sociales. 2005, n. 57, p. 455-469.

GIL-RO BLES Y GIL-DELGADO, A. "Los derechos de los ciudadanos en el Sistema Sanitario". Revista Derecho y Salud, 1994, julio-diciembre, 2(2).

GÓMEZ MARTíN, M. La libre prestación de servicios sanitarios en Europa. A propósito de las sentencias del Tribunal de Justicia de 12 de julio de 2001. Revista Derecho y Salud, no 10, 2002. 
HURTADO GONZÁLEZ, en "Derecho a la protección de la salud y derecho a la asistencia sanitaria de la Seguridad Social", Tribuna Social, no 78, 1997.

IGLESIAS, P. "Sistema nacional de dependencia". Revista del M inisterio de Trabajo y A suntos Sociales. 2006, n. 60, p. 87-92.

LEÓN, M. "La atención a las personas en situación de dependencia en España: una aproximación crítica al Libro Blanco de la Dependencia". Panorama social. 2005, n. 2, p. 34-44.

LÓPEZ CASASNOVAS, G. Envejecimiento y dependencia, situación actual y retos de futuro. Barcelona: Caixa Catalunya, 2005.

MENÉNDEZ REXACH , A., "El derecho a la asistencia sanitaria yel régimen de las prestaciones sanitarias públicas. Revista de Derecho y Salud, Vol. 11. Extraordinario XI Congreso Derecho y Salud, 2003.

NAVARRO GARZÓN, M. "Atención a las situaciones de dependencia en Andalucía: una visión panorámica". Revista del M inisterio de Trabajo y Asuntos Sociales. 2006, n. 60, p. 93-105.

ORTIZ DE ELGEA GOICOECHEA, P.J. "La asistencia sanitaria en la Unión Europea y la libre circulación de usuarios". Revista Derecho y Salud, Vol. 11, Extraordinario XI Congreso Derecho y Salud, 2003.

PALO MEQUE LÓPEZ, M., “Los Derechos a la Seguridad Social y a la Salud en la Constitución", en Derecho del Trabajo y de la Seguridad Social en la Constitución, Estudios de Trabajo y Previsión, Centro de Estudios Constitucionales, Madrid, 1980.

PEMÁN GAVÍN, J. “Las prestaciones sanitarias públicas: configuración actual y perspectivas de futuro". Revista de Administración Pública, núm. 156, septiembre-diciembre, 2001.

PFAU-EFFIN GER, Birgit; GEISSLER, Birgit(eds.) Care and social integration in European societies. Bristol: Policy Press, 2005.

PINAZO HERNANDIS, S.; SÁNCHEZ MARTIINEZ, M. Gerontología: actualización, innovación y propuestas. Madrid: Pearson Educación, 2005. 
QUADRA-SALCEDO JANINI, T.; SUÁREZ CORUJO, B. “La garantía de los derechos sociales en la Constitución europea, la consagración de la dependencia como contingencia protegida por los sistemas de seguridad social". Revista del M inisterio de Trabajo y Asuntos Sociales. 2005, n. 57, p. 471-502.

RODRÍGUEZ CABRERO, G.; RENES AYALA, V. ( coords.) . “La protección social de la dependencia en España". Documentación social. 2006, n. 141, p. 3-171.

RODRÍGUEZ CABRERO, G. "La protección social de las personas dependientes como desarrollo del Estado del bienestar en España". Panorama social. 2005, n.2, p. 21-33.

RODRÍGUEZ GARCÍA, C. "N uevas iniciativas en la provisión de cuidadosa las personas mayores: el cheque asistencial de la Comunidad Autónoma de Galicia". Panorama social. 2005, n. 2, p. 63-71.

ROMÁN VACA, E., Asistencia sanitaria de la Seguridad Social, asistencia externa y reintegro de gastos médicos, Edersa, Madrid, 1998.

SOLANES CORELLA, A., "El padrón municipal como mecanismo de inclusión de los extranjeros indocumentados", Nuevas perspectivas del régimen local: estudios en homenaje al profesor José Ma Boquera O liver / coord. por José María Baño León, Juan Climent Barberá, 2002, ISBN 84-8442-453-7, págs. 1033-1054.

SOLER MARTÍN, M.J. (coord.). "La atención a las personas en situación de dependencia". Trabajo social hoy. 2005, monográfico (2osemestre), p. 5-223.

SUERO SALAMANCA, J.A. "Estudio sobre el padrón municipal de habitantes", Actualidad Administrativa, ISSN 1130-9946, № 15, 1999, págs. 417-435.

TORRES PÉREZ, J.A. "Libro blanco para las personas en situación de dependencia". Revista de M inisterio de T rabajo y Asuntos Sociales. 2006, n. 60, p. 47-56.

TOWNSEND, Peter. "Policies for the aged in the 21st century: more «structured dependency» or the realisation of human rights?". A geing and society. 2006, v. 26, n. 2, p. 161-179.

VIDA FERNÁNDEZ, J. Las carteras de servicios: concreción, racionalización y articulación del contenido de las prestaciones sanitarias. Revista Derecho y Salud, no 13, 2005. 